NBER WORKING PAPER SERIES

\title{
MARKET PENETRATION COSTS AND THE NEW CONSUMERS MARGIN IN INTERNATIONAL TRADE
}

\author{
Costas Arkolakis \\ Working Paper 14214 \\ http://www.nber.org/papers/w14214
NATIONAL BUREAU OF ECONOMIC RESEARCH
1050 Massachusetts Avenue
Cambridge, MA 02138
August 2008

I am grateful to my advisors Timothy Kehoe and Samuel Kortum for their continued guidance and their support. I am also grateful to Cristina Arellano and Jonathan Eaton for continuous encouragement and various discussions on the topic. I am indebted to Jonathan Eaton, Samuel Kortum and Francis Kramarz for providing me with statistics from their data. For their suggestions and comments, I also would to like to thank George Alessandria, Marios Angeletos, Ariel Burstein, Thomas Chaney, V.V. Chari, John Dalton, Thomas Holmes, Christos Ioannou, Patrick Kehoe, Erzo G.J. Luttmer, Ellen McGrattan, Marc Melitz, Fabrizio Perri, Edward C. Prescott, James Schmitz, Robert Shimer, Ina Simonovska, Farid Toubal as well as various workshop and seminar participants. Financial support from the Heller Dissertation Fellowship is gratefully acknowledged. All remaining errors are mine. The views expressed herein are those of the author(s) and do not necessarily reflect the views of the National Bureau of Economic Research.

NBER working papers are circulated for discussion and comment purposes. They have not been peerreviewed or been subject to the review by the NBER Board of Directors that accompanies official NBER publications.

(C) 2008 by Costas Arkolakis. All rights reserved. Short sections of text, not to exceed two paragraphs, may be quoted without explicit permission provided that full credit, including $\odot$ notice, is given to the source. 
Market Penetration Costs and the New Consumers Margin in International Trade

Costas Arkolakis

NBER Working Paper No. 14214

August 2008

JEL No. F12,F15,L11,M3

\begin{abstract}
$\underline{\text { ABSTRACT }}$
I develop a new theory of marketing costs and introduce it into a model of trade with product differentiation and firm productivity heterogeneity. In this model, a firm enters a market if it makes profits by reaching a single consumer there and pays an increasing marginal cost to access additional consumers. This market penetration cost introduces an extensive margin of new consumers in firms' sales. I calibrate the key parameters of the model to match data on French firms from Eaton, Kortum and Kramarz, in particular the higher sales in France of firms that choose to export to more destinations. The model predicts that most firms do not export, and that a large proportion of firms that export in particular markets do so in small amounts. These predictions are in line with the French data, but together create a puzzle for models with a fixed cost of exporting, such as those of Melitz and Chaney. Looking at the comparative statics of trade liberalization, I find that the model predicts large increases in trade in goods with positive but little previous trade, in line with Kehoe and Ruhl. The model implies that these increases can contribute to new trade significantly more than the corresponding increases due to new exporters.
\end{abstract}

Costas Arkolakis

Department of Economics

Yale University

P.O. Box 208264

New Haven, CT 06520-8264

and NBER

costas.arkolakis@yale.edu 


\section{Introduction}

Recent empirical research using firm and plant level data has established that firms face substantial hurdles when selling to foreign markets: exporters tend to be in the minority, are on average more productive and larger, and usually export only a small fraction of their output. To account for the variation of firms' entry and performance accross markets, recent new theories such as those proposed by Eaton and Kortum (2002) and Bernard, Eaton, Jensen, and Kortum (2003) incorporate CES Dixit-Stiglitz demand (product differentiation) and heterogeneity in firms' productivities together with standard "iceberg" variable costs of trade. The addition of the assumption of a fixed cost of entry to a country (market penetration cost) by Melitz (2003) and Chaney (2007) has been shown by Eaton, Kortum, and Kramarz (2005) to be crucial in order to also account for the positive association between market size and firm entry. The above assumptions together with firms' productivities being Pareto distributed yield results consistent with features of firm level data for large exporters in each given destination, while creating an extremely tractable framework applicable to a variety of exercises.

This paper proposes a new formulation of market penetration costs in a model of trade with CES demand and firm productivity heterogeneity. This formulation intends to broadly capture marketing costs that the firm incurs in order to increase its sales in a given market. In the context of the model, these costs are formulated building on seminal contributions in the advertising literature such as those of Butters (1977) and Grossman and Shapiro (1984). The formulation that I introduce implies that market penetration costs are endogenous rather than fixed in the sense that paying higher costs allows firms to reach an increasing number of consumers in a country. Yet, once a consumer is reached, these costs remain fixed with the amount sold per consumer. The interaction between the per-consumer marketing cost and the variable cost of trade excludes firms with low productivity from individual export markets, if their per-consumer revenue is not sufficient to cover the cost to reach the very first consumer there.

The new formulation allows my model to retain the main desirable predictions of the fixed cost models of Melitz (2003) and Chaney (2007) while it implies large deviations on the behavior of relatively small firms to each given destination. In fact, I prove that the (uniform) fixed cost model postulated by the previous literature corresponds to a version of my model with constant 
marginal costs to reach additional consumers. In addition, assuming that with each additional marketing effort a firm reaches a smaller number of new consumers implies that there exist increasing marginal costs to reach additional consumers. This is in line with empirical evidence indicating diminishing returns to marketing outlays of firms. It gives rise to an extensive margin of consumers in the sales of the firm, namely the number of consumers that firms with different productivities sell to. Furthermore, in order to capture effects of market saturation, I also assume that this number becomes smaller at some geometric rate as the firm reaches larger fractions of consumers in a market. This allows for a particular convexity of the marginal cost function which in turns implies large departures from the CES demand structure only for the relatively smaller firms. Each of these firms exhibits substantial differences in the number of consumers reached. However, for relatively large firms that find it profitable to reach almost all consumers, the model behaves as the model with the standard CES demand.

Previous literature has postulated that firms incur significant fixed costs to export. For example, Das, Roberts, and Tybout (2005), examine a sample of Colombian exporters for the period of 1981 to 1991. Using a dynamic model, they estimate (one-time) fixed costs for new exporters ranging between $\$ 300,000$ and $\$ 500,000$ per firm. Yet, Eaton, Kortum, and Kramarz (2005) (henceforth EKK05) report that in 1986, the smallest 25\% of French exporters in a particular market each sold below $\$ 10,000$ in that market. My model reconciles the typically large estimates of fixed costs with evidence on the existence of many firms exporting small amounts to particular markets through the extensive margin of consumers mechanism. Relatively productive firms choose to reach a large number of consumers in a market, thus incurring large market penetration costs there. Relatively unproductive firms (yet productive enough to reach the very first consumer in the market) choose to reach only a few consumers in the market and thus export tiny amounts.

To quantitatively assess the model, I calibrate its key parameters to match data on French firms from EKK05. In particular, I calibrate the parameters of the model determining the relative sales of different firms to match the higher sales per firm in France of firms that also export to more markets. The remaining parameters of the model are calibrated to generate the relationship between the number of French firms entering exporting markets and the size of these markets, as reported by Eaton, Kortum, and Kramarz (2004) (henceforth EKK04) and EKK05. 
In particular, the number of French firms, normalized by French market share, and the average sales per firm increase with the size of the exporting market.

In order to corroborate the last fact, EKK05 find it essential to incorporate market-specific fixed costs that increase with the size of the market with an elasticity less than one. Instead, I model market penetration costs as a common marketing technology available to all firms. I use two realistic assumptions related to this technology, namely that there are increasing returns to scale with respect to population size of each market and that marketing costs are partially paid in terms of the importing country's wages. Given these assumptions, my model provides an intuitive explanation of the finding reported by EKK05 as the result of the optimal marketing decision of firms aiming to reach consumers in markets with different population or per capita income.

The calibrated model with endogenous market penetration costs is able to deliver a series of new predictions. I use this new approach, without assuming any other source of firm heterogeneity, to address existing puzzles in international trade theory.

First, the distribution of small firms' sales at each given destination exhibits large deviations from the Pareto distribution. Given the CES structure and Pareto distribution of productivities, this deviation is a result of the increase in sales of the relatively small firms that is faster than proportionate. Furthermore, the distribution of large firms' sales to a given destination is Pareto. Mechanically, this is because relatively unproductive firms endogenously select a small number of consumers while large firms reach almost all the consumers in the market. In fact, some firms find it optimal not to enter a market since reaching the first consumer is not profitable for them. Thus, the model quantitatively accounts for the small amounts exported by a large proportion of the French firms in each market, while it still predicts that most French firms do not export. The small export volume of many firms has been especially puzzling to the fixed cost model with CES demand structure and Pareto distribution of productivities.

Second, deviation from the CES structure has important implications regarding the comparative statics of trade liberalization. To illustrate this I extend the methodology of Kehoe and Ruhl (2003) to data on goods that were positively traded prior to the US-Mexico liberalization episode. I find that the growth rate of the volume of trade of goods is larger the less traded the goods are before the liberalization. This feature of the data is in sharp contrast with the 
predictions of existing models of trade that rely solely on the CES Dixit-Stiglitz demand specification such as the fixed cost model. These models predict constant growth rates of trade for all previously positively traded goods, given uniform elasticity of substitution between goods. In fact, models of this kind were used to predict trade patterns in the case of the NAFTA episode and they were unable to predict the high growth rates of sales, especially for goods with little trade prior to the trade liberalization, as Kehoe (2005) points out. I use my model to look at the comparative statics of trade liberalization, with parameters calibrated to the French data and a symmetric change in the variable trade costs across goods calibrated to match the overall increase in trade following the US-Mexico liberalization episode. The model turns out to capture the higher growth rate in trade for goods with positive but little previous trade.

Finally, I study a new margin of response of aggregate trade flows to decreases in trade costs. This "new consumers" margin is meant to capture the faster growth of small existing exporters after a trade liberalization. In my analysis, I decompose the contribution of the three margins to new trade, the "new consumers" margin, the intensive margin of growth in per consumer sales, emphasized by Krugman (1980), and the new firms margin analyzed by Eaton and Kortum (2002), Melitz (2003) and Chaney (2007). I find that a considerable amount of new trade is generated by new firms and by sales of previously exporting firms to new consumers. However, for small changes in variable trade costs, the contribution of the new consumers margin to new export sales is larger than the contribution of the new firms margin. New firms entering a market, although numerous, sell a tiny amount.

In summary, this paper is a continuation of the abovementioned theoretical literature incorporating firm level heterogeneity into international trade theory. This literature has emerged in response to the recent use of firm and plant level data to measure the behavior of exporters along many dimensions (see, for example, Bernard and Jensen (1995), Clerides, Lach, and Tybout (1998), Aw, Chung, and Roberts (2000), or Tybout (2001) for a review). The empirical facts summarized by this literature indicate that there exist substantial costs of exporting, as EKK04 point out. EKK05 find that in order to account for a variety of facts related to French exporters, export costs have to take the form of both variable costs, that rise in proportion to the amount shipped, and fixed costs as in Melitz (2003) and Chaney (2007). In this paper, I propose a new approach to modeling market penetration costs of exporting based on a new 
formulation of marketing costs. This approach, while consistent with the trade data, departs from the assumption of fixed costs of exporting.

The outline of the rest of the paper is as follows: In section 2, I describe the model and the new formulation of marketing costs in detail. In section 3 , I calibrate the model using a methodology developed by EKK05. In section 4 and 5 I quantitatively assess the predictions of the calibrated model. Section 6 concludes.

\section{Model}

In this section I introduce the model with endogenous market penetration costs. This model incorporates the assumptions of product differentiation and firm productivity heterogeneity using the monopolistic competition framework proposed by Melitz (2003) and Chaney (2007). It departs, however, from the existing literature in the demand structure since the fraction of consumers who have access to a firm's good is the result of a decision on the part of the firm. Each firm has to pay an increasing cost to reach additional consumers in a given market and chooses the number of its consumers in order to maximize its profit.

\subsection{Consumer problem and demand for goods}

I denote the source country by $i$ and the destination country by $j$ where $i, j=1, \ldots, N$. Country $j$ is populated by a continuum of consumers of measure $L_{j}$. Consumers derive utility from the consumption of a continuum of goods indexed by $\omega$, according to a symmetric CES utility function,

$$
U^{l}=\left(\int_{\omega \in \Omega^{l}} x(\omega)^{\rho} d \omega\right)^{\frac{1}{\rho}}, 0<\rho<1,
$$

where $\Omega^{l}$ is the set of goods consumer $l \in L$ has access to. $\Omega^{l}$ is a potential subset of the set of all the goods sold in the economy $\Omega$.

Each good is produced by a single firm and firms differ ex-ante only in their productivities and their source country $i$. I consider a symmetric equilibrium where all the firms with the same productivity, $\phi$, from the same source country, $i$, charge the same price in destination country $j, p_{i j}(\phi)$, and the same probability that they reach a consumer there, $n_{i j}(\phi)$, in a manner that 
I will describe in the next paragraph. I will therefore refer to the type of the firm (good) by its productivity, $\phi$, and when necessary by its source country, $i$. Since there is a large number of firms of each productivity, each consumer has access to a fraction $n_{i j}(\phi)$ of the goods of firms with productivity $\phi$ from source country $j .{ }^{1}$ There is a measure of $J_{i}$ goods that can be potentially produced by each country, while $M_{i j} \leq J_{i}$ is the measure of firms from source coutry $i$ operating in country $j .^{2}$ The productivities of firms originating in country $i$ are drawn from a distribution with support $\left[b_{i},+\infty\right)$. I denote the density of firms from source country $i$ conditional on operating in $j$, by $\mu_{i j}(\phi)$. Given the existence of a large number of firms of each type, each consumer has access to a different set of goods, $\Omega^{l}$, but to the same measure of goods produced by firms with productivity $\phi$ from source country $i, n_{i j}(\phi) \mu_{i j}(\phi) M_{i j}$.

The representative household earns profit flows $\pi_{j}$ and labor income $w_{j}$ by (inelastically) supplying her unit labor endowment to the labor market. ${ }^{3}$ The solution to the maximization problem of the consumer gives rise to the usual CES Dixit-Stiglitz demand for each good $\phi$ (conditional on the consumer having access to it). The demand of a representative consumer from country $j$ for a type $\phi$ good from country $i$ is given by

$$
x_{i j}(\phi)=y_{j} \frac{p_{i j}(\phi)^{-\sigma}}{P_{j}^{1-\sigma}}
$$

where

$$
P_{j}^{1-\sigma}=\sum_{v=1}^{N} J_{v} \frac{b_{v}^{\theta}}{\left(\phi_{v j}^{*}\right)^{\theta}} \int_{b_{v}}^{+\infty} p_{v j}(\phi)^{1-\sigma} n_{v j}(\phi) \mu_{v j}(\phi) d \phi, \quad \sigma=\frac{1}{1-\rho}>1
$$

\footnotetext{
${ }^{1}$ This is essentially a statement of the Glivenko-Cantelli theorem, which in turn is a direct application of the Law of Large Numbers (LLN) for i.i.d random variables. In order to apply the LLN, I assume that firms reach consumers independently of each other. In the application of the LLN to the case of a continuum of i.i.d. random variables technical problems may arise (see for example the discussion in Hopenhayn (1992)). Various remedies have been suggested by different authors (see e.g Uhlig (1996) and references there). As is usual in the economics literature, I assume the applicability of the LLN without proving the exact conditions under which it applies. This is a highly technical issue beyond the scope of this paper.

${ }^{2}$ Alternatively, one can think of $J$ as the measure of differentiated varieties of goods available to firms to produce. Arkolakis, Demidova, Klenow, and Rodriguez-Clare (2008) show that the extension to a context with an unbounded pool of entrants and free entry, as in Melitz (2003), gives rise to identical predictions to one where this measure is fixed as in Chaney (2007). In an appendix available online at http://www.econ.yale.edu/ ${ }^{\sim}$ ka265/research.htm I provide the same result for my model, together with a variety of secondary facts and robustness checks about the model and the data in this paper.

${ }^{3}$ I assume that consumers own equal share of each firm originating in their country. Thus, profits of firms will be equally distributed among the consumers of their country.
} 
and $y_{j}=w_{j}+\pi_{j}$ denotes the per capita spending which equals the output per capita.

Given the existence of a large number of consumers, each firm $\phi$ reaches a fraction $n_{i j}(\phi)$ of the consumers. Total demand for a firm with productivity $\phi$ from source country $i$ and selling to country $j$ is given by

$$
n_{i j}(\phi) L_{j} y_{j} \frac{p_{i j}(\phi)^{-\sigma}}{P_{j}^{1-\sigma}}
$$

\section{$2.2 \quad$ Firm}

Each operating firm has to make two choices in order to maximize its profit in each market. The first is to produce the good. This is done using a constant returns to scale production function $q(\phi)=\phi l$, where $l$ is the amount of labor used in production and $\phi$ is the labor productivity of the firm. Delivery of the produced units of the good to a certain destination requires standard iceberg costs to be incurred in terms of labor. Thus, for a firm operating in country $i$ and selling to country $j, \tau_{i j}>1$ units of the good must be shipped in order for one unit of the good to arrive at the export destination. For simplicity, I assume that $\tau_{i i}=1 .^{4}$ This process creates the good that can be used for consumption conditional on a particular consumer having access to it. The second choice of the firm is to incurr the required costs to reach a certain fraction of consumers in each given market. This market penetration cost is described below.

\subsubsection{A theory of marketing and the market penetration technology}

Marketing costs include the costs incurred by a firm during the process of promoting its product and reaching consumers as well as establishing the related distribution channels in order to sell its product. Evidence about the exact nature of these market penetration costs for the case of exporting is provided by Keesing (1983) and Roberts and Tybout (1997). The authors discuss a number of costs reported by managers of exporting firms in a series of interviews. These data indicate that firms must research the foreign market by identifying and contacting the potential consumers of their good. Hence, they must develop new goods or adapt their existing products to foreign consumers' tastes. Finally, the firms must set up direct or indirect distribution channels in order to make the good available to the foreign consumers and to inform them about the

\footnotetext{
${ }^{4}$ I further assume $\tau_{i j} \leq \tau_{i v} \tau_{v j} \forall(i, v, j)$ to exclude the possibility of transportation arbitrage.
} 
existence of the good. ${ }^{5}$ Of course, all these costs have to be incurred in the domestic market in a similar manner.

Marketing expenditures constitute a considerable amount of the overall spending of the economy. In fact, media advertising amounts to almost 2\% of total GDP in the US for the years 2001 to 2004. Taking into account estimates indicating that media advertising spending accounts for only $40 \%$ of overall marketing spending for 2001-2004, the amount of marketing spending could be as much as $5 \%$ of GDP for these years. ${ }^{6}$ Traditional trade theory has modeled market penetration costs through a fixed cost of entry to each given market. In order to understand the role that these costs play in international trade, I will develop a formulation guided both by realistic assumptions as well as certain facts reported for marketing expenditures at the firm level.

An important ingredient of the formulation of marketing costs I introduce is decreasing returns to additional marketing expenditure. These dereasing returns may arise as (i) less responsive consumers are reached or the same consumers respond less to additional marketing efforts, or (ii) an increasing amount of effort has to be taken in order to reach a consumer that has not yet been reached. While some evidence supporting this diminishing returns assumption for marketing exists, most of the motivating studies come from evidence of the best-measured portion of marketing expenditures, i.e. advertising. In particular, in the most comprehensive study of the economics of advertising literature up to date Bagwell (2007) mentions that ${ }^{7}$

"Using various (e.g., logarithmic) measures, a number of studies regress sales on advertising and offer evidence that advertising's effectiveness is subject to diminishing returns. In essence, these studies hold other inputs constant and argue that doubled advertising results in less than doubled sales [...] On the whole, the studies that evaluate the effectiveness of advertising suggest

\footnotetext{
${ }^{5}$ Roberts and Tybout (1997) mention that firms can pay third parties to handle the distribution, which, reportedly, is very frequently the case. If this last activity is characterized by free entry, then market penetration can simply be reinterpreted as being handled by a third party hired by the firm.

${ }^{6}$ See the report on "US Advertising Volume" from Universal McCann available at http://www.universalmccann.com and the "Marketing Expenditure Trends" reports of the London Business School, available at www.london.edu/marketing/met.

${ }^{7}$ See also Lambin (1976), Simon and Arndt (1980), Sutton (1991) (e.g. p. 51) and Jones (1995). For a discussion regarding diminishing returns to marketing expenditures, see Saunders (1987). Diminishing returns to marketing are reasonable. It is eminently rational that marketing search efforts will start through marketing vehicles that will deliver the best consumer reach or the highest per consumer sales. Then, as marketing efforts increase additional marketing spending will be less efficient and marginal sales will decrease as marketing expenditure increases.
} 
that advertising often entails diminishing returns beyond a threshold level, where the threshold level varies across circumstances and may be small."

The foundation of my theoretical approach will be twofold. On the one hand, I will retain the framework with product differentiation and productivity heterogeneity that has proven extremely useful in trade models. On the other hand, I will develop a consistent framework that captures the stylized fact about marketing mentioned above while generalizing the seminal contributions of Butters (1977), Grossman and Shapiro (1984). ${ }^{8}$ In this framework I envision a cost of market penetration as the cost of reaching a consumer in that market, while this cost could be thought as isomorphic to the one of example (i) that was laid out above. ${ }^{9}$ The simple marketing technology that I derive from first principles has two key properties. It implies increasing marginal costs to reach additional consumers in a market and increasing elasticity of the marginal cost function. The parameterization of the marketing cost function regulates the convexity of the marginal cost function. While the increasing elasticity property deviates from the case of constant elasticity of less than unity that the empirical studies mentioned above would suggest, qualitatively the two approaches give the same results for the key questions that I consider. In addition, the formulation with this last property also allows me to capture a market saturation effect without any additional modeling. ${ }^{10}$ It finally allows for the possibility of constant marginal costs of reaching additional consumers that is shown to encapsulate the standard uniform fixed cost framework.

In my analysis, I have to pay particular attention to how the marketing cost to reach a number of consumers in a country varies across countries (assuming that the cost of sending an ad is the same across countries). I view countries as distinct markets such that marketing expenditures incurred for one market cannot influence the demand of the firm in another one. The crucial assumption of diminishing returns in marketing expenditure has to be modeled carefully for

\footnotetext{
${ }^{8}$ See also Stegeman (1991). A more recent paper that comes closer to my approach is Dinlersoz and Yorukoglu (2006). The authors introduce informative advertisement of a homogeneous good produced by a continuum of firms with heterogeneous productivities.

${ }^{9}$ In the online appendix I show that there exists an isomorphism with the case of marketing expenditures that affect the sales per consumer rather than the number of consumers reached.

${ }^{10}$ Assuming that doubling marketing costs implies less than doubling sales can be explicitly modeled in our context with the function $f+n^{\beta}, f>0, \beta>1$ and an upper bound on $n$ to capture the effect of saturation. It is straightforward to show that this assumption will qualitatively generate the same deviations from the CES demand structure as the ones that the function I introduce below delivers. However, quantitatively and methodoligically this approach is clearly inferior.
} 
countries with different populations, denoted by $L$. In particular, I have to allow the possibility that the marketing technology exhibits increasing returns to scale with respect to the population size of each market. To simplify the argument, I lay out two extreme examples. First, I describe the case of advertising with flyers where each flyer can be given to at most one consumer. This implies that in order to reach a given number of consumers, the total spending is the same and is independent of the size of the market. Second, I describe the case of TV advertisements, which I assume reach a given fraction of the consumers in any given market. In this case, a firm can reach double the number of consumers in a country that is twice as large using the same number of advertisements. My analysis incorporates both extremes as well as all intermediate cases.

For simplicity of exposition I will model marketing technology drawing on a simple example of informative advertisment, where the advertisement (ad) sent by a firm is essentially a posting that contains information about the existence of the good and its price. I start my exposition by laying the flyers example laid out above and by considering the case where variables are discrete. I denote by $S$ the number of advertising signals sent by a firm. Further, I assume that the firm sends advertising signals to the consumers independently of other firms. I assume that potential consumers are not aware of the price a particular firm charges unless they observe a signal sent by the firm. I denote by $n(S)$ the probability that a consumer sees the ad at least once after $S$ signals have been seen and I let $n(0)=0 .{ }^{11}$ Assuming that each new ad reaches one consumer and that the probability that each ad is seen for the first time by a consumer is proportional to the percentage of people that did not see the ad up to now (ad is randomly thrown),

$$
[n(S+1)-n(S)] L=1-n(S)
$$

The discrete example, though intuitively appealing, cannot be directly adapted in the context of my model. Thus, I consider the analog of the above expression for $S, L$ being continuous variables and $n(S)$ a continuous and differentiable function,

$$
n^{\prime}(S) L=1-n(S)
$$

\footnotetext{
${ }^{11}$ In the context of the maximization problem of the firm, the amount of marekting of the firm is ultimately a function of its productivity and thus, $S=S(\phi), n=n(\phi)$. Here, I describe a general technology and suppress the $\phi$ notation until I consider the optimal decision of a type $\phi$ firm.
} 
Solving this differential equation subject to the initial condition $n(0)=0$ gives $n(S)=1-$ $\exp \{-S / L\}$. Inverting this function implies that the number of ads needed to reach a fraction $n$ of the consumers in a market of size $L$ is given by $S=-L \log (1-n)$.

To generalize the simple case above, I make two distinct assumptions:

Assumption 1 The probability that a consumer sees an ad she has not seen before is given by

$$
[1-n(S)]^{\beta}, \beta \in[0,+\infty)
$$

Assumption 2 The number of consumers who see each ad is given by

$$
L^{1-\alpha}, \alpha \in[0,1]
$$

The first assumption captures the diminishing returns to marketing expenditures. Notice that higher values of $\beta$ correspond to more intense diminishing returns. In the case of $\beta=0$, the returns to marketing are constant, which implies a constant marginal cost to reach additional consumers.

The second assumption captures the possibility that with a given an ad a firm can potentially inform a larger number of consumers about its good in a larger market. The example of TV ads outlined above corresponds to letting the parameter $\alpha=0$, while the flyers example to that of $\alpha=1$. The intermediate cases emerge when $\alpha \in(0,1)$.

Using the two assumptions stated earlier, the technology for reaching new consumers through ads becomes

$$
n^{\prime}(S) L=L^{1-\alpha}[1-n(S)]^{\beta}
$$

which incorporates the possibility of returns to scale in marketing technology $\left(L^{1-\alpha}\right)$ and also allows for increasing marginal costs to reach additional consumers $\left([1-n(S)]^{\beta}\right)$. Solving this differential equation subject to the initial condition $n(0)=0$ gives

$$
n(S)=1-\left(1-(-\beta+1) \frac{S}{L^{\alpha}}\right)^{1 /(-\beta+1)}
$$

Inverting this last expression and solving for $S$ gives the amount of advertising required by a 
firm aiming to reach a fraction $n$ of the consumers in a market of size $L$. Assuming the labor requirement for each ad is $1 / \psi$, the labor cost of reaching $n$ consumers in a market of size $L$ (market penetration cost) becomes

$$
f(n, L)=\frac{L^{\alpha}}{\psi} \frac{1-(1-n)^{-\beta+1}}{-\beta+1}, \alpha \in[0,1]
$$

This is the marketing cost function that I will use in the rest of the paper and thus I delve into its properties. The marginal cost function is illustrated in figure 1 for different values of $\beta$. For the case of $\beta>0$, the following conditions hold:

$$
\begin{gathered}
f_{1}(n, L)>0, f_{11}(n, L)>0, \\
\left.\lim _{n L \rightarrow 0} \frac{\partial f(n, L)}{\partial(n L)}\right|_{L=\bar{L}}=\frac{L^{\alpha-1}}{\psi}>0 .
\end{gathered}
$$

Expression (6) implies that the marginal cost of reaching new consumers is positive and is increasing in the fraction of consumers reached. Expression (7) indicates that the cost to reach the very first, or marginal, consumer is positive. The elasticity of the marginal cost function is larger the larger the fraction of consumers already reached, while the limit of the marginal cost function as $n \rightarrow 1$ tends to infinity and thus no firm can saturate the market. Given the CES demand, this implies that the model will behave similar to a standard model for the relatively large firms that reach almost all the consumers. Notice that, for $\beta=0$, the marginal cost of reaching additional consumers is constant. Below, I will show that in the case in which $\beta=0$ my model corresponds to the case of the theory with a fixed cost of exporting.

\subsubsection{Marketing costs in terms of foreign and domestic labor}

For the marketing activities related to exporting described above, the importing country's labor is oftentimes employed (see Keesing (1983) and Roberts and Tybout (1997)). For example, creating distribution channels in importing countries may require hiring foreign labor for advertising

purposes. Hence, the market penetration costs are paid in terms of the importing country's wages. Yet, there is substantial evidence that part of the labor costs for marketing expenditures are paid in terms of the exporting country's wages. Therefore, I choose to combine this evidence 
and consider a general case in which the market penetration cost of each firm is denominated both in importing and exporting country's wages. I make the following assumption:

Assumption 3 The production of marketing requires a bundle of labor services from source country $i$ and destination country $j$ :

$$
S=l_{j}^{\gamma} l_{i}^{1-\gamma}, 0<\gamma<1
$$

For simplicity, I also assume that $\gamma$ is the same across countries. I will estimate the value of all the parameters using trade data in section 3 . The total cost of a firm from source country $i$ to reach a fraction $n_{i j}(\phi)$ of the consumers of country $j$ with population size $L_{j}$ is given by the following expression (taking into account cost minimization by the firm): ${ }^{12}$

$$
w_{j}^{\gamma} w_{i}^{1-\gamma} \frac{L_{j}^{\alpha}}{\psi} \frac{1-\left[1-n_{i j}(\phi)\right]^{-\beta+1}}{-\beta+1}
$$

\subsubsection{Firm's problem}

Given the above, the problem that a firm with productivity $\phi$ from source country $i$ solves when considering whether to sell to market $j$ is given by

$$
\begin{aligned}
\pi_{i j}(\phi)= & \max _{n_{i j}, p_{i j}}\left\{n_{i j} L_{j} y_{j} \frac{p_{i j}^{1-\sigma}}{P_{j}^{1-\sigma}}-n_{i j} L_{j} y_{j} \frac{\tau_{i j} p_{i j}^{-\sigma} w_{i}}{P_{j}^{1-\sigma} \phi}-w_{j}^{\gamma} w_{i}^{1-\gamma} \frac{L_{j}^{\alpha}}{\psi} \frac{1-\left(1-n_{i j}\right)^{-\beta+1}}{-\beta+1}\right\} \\
& \text { s.t. } n_{i j} \in[0,1] .
\end{aligned}
$$

Total profits of a particular firm are the summation of the profits from exporting activities in all the $j=1, \ldots, N$ countries (or a subset thereof). For the case where $\beta \geq 0$, the optimal decisions of the firm in the multi-country model are (using the results of Proposition 1):

$$
p_{i j}(\phi)=\tilde{\sigma} \frac{\tau_{i j} w_{i}}{\phi}, \tilde{\sigma}=\frac{\sigma}{\sigma-1}
$$

Given this markup rule, the optimal market penetration decision for a firm with productivity

\footnotetext{
${ }^{12}$ For simplicity, I redefine per unit advertisment costs $1 / \psi$ to incorporate an extra term $\gamma^{\gamma}(1-\gamma)^{1-\gamma}$.
} 
$\phi, n_{i j}(\phi)$, for the case in which $\beta>0$, is given by the FOC with respect to $n_{i j}$. Thus, for $\phi \geq \phi_{i j}^{*}$, the optimal $n_{i j}$ solves $^{13}$

$$
\underbrace{\frac{y_{j}}{\sigma} \frac{\left(\tilde{\sigma} \frac{\tau_{i j} w_{i}}{\phi}\right)^{1-\sigma}}{P_{j}^{1-\sigma}}}_{\begin{array}{c}
\text { marginal revenue (net } \\
\text { of labor production } \\
\text { cost) per consumer }
\end{array}}=\underbrace{\frac{w_{j}^{\gamma} w_{i}^{1-\gamma} L_{j}^{\alpha-1}}{\psi} \frac{1}{\left[1-n_{i j}\right]^{\beta}}}_{\begin{array}{c}
\text { marginal cost } \\
\text { per consumer }
\end{array}},
$$

where $\phi_{i j}^{*}$ is given by ${ }^{14}$

$$
\phi_{i j}^{*}=\sup _{\phi \geq b_{i}}\left\{\pi_{i j}(\phi)=0\right\}
$$

In order to decide whether to enter a market or not, a firm compares the marginal revenue received from the very first consumer with the corresponding marginal cost of reaching her. The LHS of equation (9) represents the marginal revenue (net of labor production costs) from selling to an additional consumer. Due to elastic demand, more productive firms can charge lower prices and extract higher marginal revenue per consumer. The RHS of the same equation captures the corresponding marginal cost to reach an additional consumer. The marginal cost of reaching the very first consumer in market $j$ is the RHS of expression (9) evaluated at $n_{i j}=0$ (as in equation (7)). Alternatively, one can think of this marginal cost as the expected cost of sending the first advertisement divided by the number of people that see this first advertisement,

$$
\frac{\text { cost of the first ad }}{\text { expected number of people that see the ad }}=\frac{w_{j}^{\gamma} w_{i}^{1-\gamma} / \psi}{L_{j}^{1-\alpha}} \text {. }
$$

For the case in which $\alpha<1$, the cost to reach the first consumer falls as the population increases since the denominator in expression (11) increases. This allows firms with lower productivities, which have smaller sales per consumer (see the RHS of (9)), to enter a market with a larger population. Thus, for $\alpha<1$, bigger markets will attract more firms.

Figure 2 plots the marginal revenue per consumer (net of labor costs) and the marginal cost

\footnotetext{
${ }^{13}$ In order to interpret the LHS and RHS of expression (9) as marginal revenue and marginal cost per consumer, the derivative with respect to $n_{i j} L_{j}$ has to be applied.

${ }^{14} \mathrm{I}$ assume that parameters of the model are such that $b_{i} \leq \min _{j} \phi_{i j}^{*}$.
} 
per consumer. To simplify notation I consider the one country case in the rest of the paragraph, without any loss of generality. The point of intersection in figure 2 corresponds to the solution to equation (9). This intersection gives $n(\phi)$ as a function of $\phi$ for the case of $\beta>0$. Notice that since marginal revenue per consumer is higher for higher values of $\phi$, more productive operating firms find it profitable to pay the cost to reach a higher fraction of consumers. ${ }^{15}$ Moreover, given the price level $P$, there exists a threshold productivity $\phi^{*}$ such that $\forall \phi \leq \phi^{*}, n(\phi)=0$. This results from the fact that for such low $\phi$ 's, the very low marginal revenue net of labor production costs from the first consumer is not sufficient to cover the cost to reach her. However, when the marginal cost to reach an additional consumers is constant, namely when $\beta=0$, the decision rule is no longer continuous. Firms with $\phi \leq \phi^{*}$ choose $n(\phi)=0$ and firms with $\phi>\phi^{*}$ choose $n(\phi)=1$, resulting in the same decision rule as in the theory with fixed costs of Melitz (2003) and Chaney (2007) The following proposition summarizes the above discussion:

\section{Proposition 1}

a) If $\beta>0$, then

i) there exists a threshold $\phi^{*}$ such that $\forall \phi \leq \phi^{*}, n(\phi)=0$,

ii) $\phi_{1}>\phi_{2} \Longrightarrow n\left(\phi_{1}\right)>n\left(\phi_{2}\right), \forall \phi_{1}, \phi_{2} \geq \phi^{*}$.

b) If $\beta=0$, then

$n(\phi) \in\{0,1\}$ and there exists $\phi^{*}$ such that $\forall \phi \leq \phi^{*}, n(\phi)=0$, and $\forall \phi>\phi^{*}, n(\phi)=1$.

Proof. a) Part $i$ ) This part is proved formally in appendix A. Also, notice that by solving (9) for $n(\phi)>0$, we have

$$
n(\phi)=1-\left[L^{1-\alpha} y \phi^{\sigma-1}(\tilde{\sigma} w)^{1-\sigma} \psi P^{\sigma-1} /(w \sigma)\right]^{-1 / \beta}
$$

\footnotetext{
${ }^{15} \mathrm{~A}$ direct implication of the combination of the assumption of the diminshing returns to marketing expenditures and firm heterogeneity is that the marketing to sales ratio will be higher for firms with lower sales. A variety of studies reports evidence supporting this prediction (see for example Farris and Buzzell (1979), Arndt and Simon (1983) and Thomas (1989)). Interestingly enough, this empirical evidence led many researchers to hypothesize that larger firms are more efficient in marketing, a claim not supported in any convincing way by other empirical tests as Arndt and Simon (1983) point out. My model generates lower marketing to sales ratios for firms with higher sales, even though every firm has access to the same marketing technology.
} 
Define

$$
\left(\phi^{*}\right)^{\sigma-1}=\left[L^{1-\alpha} y(\tilde{\sigma} w)^{1-\sigma} \psi P^{\sigma-1} /(w \sigma)\right]^{-1}
$$

such that $\forall \phi>\phi^{*}, n(\phi)>0$. For $\phi \leq \phi^{*}$, as shown in appendix A, $n(\phi)=0$. The above proves part $i$ ) of $a$ ).

a) Part ii) From equation (9) and the proof of uniqueness in appendix A, part ii) follows. ${ }^{16}$

b) As long as $\beta=0$, the marginal cost of reaching an additional consumer $w L^{\alpha-1} / \psi$ is constant with respect to $n(\phi)$. Thus, every consumer brings the same marginal profit to the firm. Therefore, the firm chooses $n(\phi)=1$ if this profit is positive for all the consumers, and $n(\phi)=0$ otherwise. Since this marginal profit is strictly increasing in $\phi$, part $b$ ) follows. ${ }^{17}$

\subsection{Equilibrium}

I define the cdf and the pdf of the distribution of the productivities of firms by $G_{i}(\phi)$ and $g_{i}(\phi)$ respectively, with support $\left[b_{i},+\infty\right)$. The probability that a firm is actually operating in the economy corresponds to the probability that a firm has a productivity draw $\phi$ such that $\phi \geq \phi_{i j}^{*}$, namely $1-G_{i}\left(\phi_{i j}^{*}\right)$. Thus, the measure of operating firms is given by $J_{i}\left[1-G_{i}\left(\phi_{i j}^{*}\right)\right]$. The pdf of the conditional distribution of firms is given by

$$
\mu_{i j}(\phi)=\left\{\begin{array}{cc}
\frac{g_{i}(\phi)}{1-G_{i}\left(\phi_{i j}^{*}\right)} & \text { if } \phi \geq \phi_{i j}^{*} \\
0 & \text { otherwise. }
\end{array}\right.
$$

I can now summarize the above discussion and define an equilibrium.

Given the number of potential entrants $J_{i}$ from country $i$, an equilibrium for each $i, j=$ $1, \ldots, N$ is given by a lower bound threshold productivity $\hat{\phi}_{i j}^{*}$; the measure of firms operating in

\footnotetext{
${ }^{16}$ In a model with heterogeneous productivity firms but homogeneous goods, Dinlersoz and Yorukoglu (2006) also arrive at the conclusion that more productive firms reach a higher number of consumers in the country. However, their mechanism is different. In their model, each new advertisement is seen by one consumer with certainty, but costs of sending additional advertisements are considered to be convex. Firms that charge lower prices have higher probability of being the cheaper option for the consumer who sees their advertisement. Thus, the expected revenue of each advertisement is higher for more productive firms that can charge lower prices, and they choose to reach more consumers.

${ }^{17}$ In the case of $\beta<0$ there are decreasing marginal costs to reach additional consumers. Thus, firms choose either $n(\phi)=0$ or $n(\phi)=1$ as in the case of $\beta=0$. Therefore, without loss of generality, I do not have to analyze the case where $\beta<0$.
} 
each economy $\hat{M}_{i j}$; the pdf of the distribution of firms productivities, conditional on operating, $\hat{\mu}_{i j}(\phi)$, prices $\hat{p}_{i j}(\phi), \forall \phi \in\left[b_{i},+\infty\right)$; a wage rate $\hat{w}_{i}$; a per consumer profit $\hat{\pi}_{i}$; a price index $\hat{P}_{i}$; a consumption plan for the representative consumer $\hat{x}_{i j}(\phi)$ and a production plan for each firm $\hat{q}_{i j}(\phi), \hat{n}_{i j}(\phi), \forall \phi \in\left[b_{i},+\infty\right)$ such that:

- Given $\hat{P}, \hat{w}, \hat{\pi}$ and $\hat{p}(\phi)$, the representative consumer solves her maximization problem by choosing $\hat{x}_{i j}(\phi)$ for the goods $\phi$ she has access to according to

$$
x_{i j}(\phi)=\hat{y}_{j} \frac{\hat{p}_{i j}(\phi)^{-\sigma}}{\hat{P}_{j}^{1-\sigma}}, \hat{y}_{j}=\hat{w}_{j}+\hat{\pi}_{j}
$$

- Given $\hat{P}, \hat{w}, \hat{\pi}$ and the indirect demand function $\hat{p}\left(q_{i j}(\phi), n_{i j}(\phi) ; \hat{P}_{j}, \hat{w}_{j}, \hat{\pi}_{j}\right)$ that comes from solving the representative consumer's utility maximization problem, firm $\phi, \forall \phi \in$ $\left[b_{i},+\infty\right]$, chooses $\hat{q}_{i j}(\phi), \hat{n}_{i j}(\phi)$ to solve

$$
\begin{aligned}
\pi(\phi)= & \max \left\{\hat{p}\left(q_{i j}(\phi), n_{i j}(\phi) ; \hat{P}_{j}, \hat{w}_{j}, \hat{\pi}_{j}\right) q_{i j}(\phi)-\hat{w}_{j} \frac{q_{i j}(\phi)}{\phi}-\hat{w}_{j}^{\gamma} \hat{w}_{i}^{1-\gamma} \frac{L_{j}^{\alpha}}{\psi} \frac{1-\left[1-n_{i j}(\phi)\right]^{-\beta+1}}{-\beta+1}\right\} \\
\text { s.t. } & q_{i j}(\phi) \leq n_{i j}(\phi) L_{j} \hat{y}_{j} \frac{\hat{p}\left(q_{i j}(\phi), n_{i j}(\phi) ; \hat{P}_{j}, \hat{w}_{j}, \hat{\pi}_{j}\right)^{-\sigma}}{\hat{P}_{j}^{1-\sigma}}, \hat{y}_{j}=\hat{w}_{j}+\hat{\pi}_{j} \\
& n_{i j}(\phi) \in[0,1]
\end{aligned}
$$

- Firms from country $i$ operate in country $j$ iff $\phi \geq \phi_{i j}^{*}$ where $\phi_{i j}^{*}$ is defined by

$$
\left(\phi_{i j}^{*}\right)^{\sigma-1}=\left[L_{j}^{1-\alpha} y_{j}^{1-\gamma}\left(\tilde{\sigma} \tau_{i j} w_{i}\right)^{1-\sigma} \tilde{\psi} P_{j}^{\sigma-1} / y_{i}^{1-\gamma}\right]^{-1}
$$

- The measure of operating firms $\hat{M}_{i j}=J_{i}\left[1-G_{i}\left(\hat{\phi}_{i j}^{*}\right)\right]$.

- The pdf of the conditional distribution of operating firms $\hat{\mu}_{i j}(\phi)$ is given by (14).

- The price index satisfies (2).

- Per consumer profit satisfies $\hat{\pi}=\sum_{v=1}^{N} \hat{M}_{i v} \int_{b}^{\infty} \hat{\pi}_{i v}(\phi) \hat{\mu}_{i v}(\phi) d \phi / L_{v}$.

- The individual goods market clears $\hat{n}_{i j}(\phi) L_{j} \hat{x}_{i j}(\phi)=\hat{q}_{i j}(\phi), \forall \phi \in\left[b_{i},+\infty\right)$. 
- The labor market clears, which given the trade balance can be shown to be equivalent to

$$
\left(w_{i}+\pi_{i}\right) L_{i}=\sum_{v=1}^{N} \lambda_{i v}\left(w_{v}+\pi_{v}\right) L_{v}
$$

where $\lambda_{i j}$ is the fraction of spending by country $j$ on goods from country $i .{ }^{18}$

To derive stark predictions from the model, I make a particular assumption regarding the distribution of productivities. Similar to Helpman, Melitz, and Yeaple (2004) and Chaney (2007), I assume that the productivity of firms is drawn from a Pareto distribution with shape parameter $\theta>\sigma-1, \operatorname{cdf} G_{i}(\phi)=1-b_{i}^{\theta} / \phi^{\theta}, \operatorname{pdf} g_{i}(\phi)=\theta b_{i}^{\theta} / \phi^{\theta+1}$ and support $\left[b_{i},+\infty\right)$, where $b_{i}$ can be interpreted as the level of technology. ${ }^{19}$ The measure of operating firms becomes $M_{i j}=$ $J_{i} b_{i}^{\theta} /\left(\phi_{i j}^{*}\right)^{\theta}$.

In the subsequent analysis I will refer to the case of $\beta=0$, that corresponds to the theory of Melitz (2003) and Chaney (2007), as the fixed cost model and to the case of $\beta>0$ as the endogenous (market penetration) cost model. I now proceed to study the total sales of firms as functions of their productivities. The total sales of a firm from country $i$ selling to country $j$ and having productivity $\phi$ are given by

$$
\underbrace{n_{i j}(\phi) L_{j}}_{\begin{array}{c}
\text { extensive } \\
\text { margin of } \\
\text { consumers }
\end{array}} \underbrace{y_{j} \frac{\left(\tilde{\sigma} \frac{\tau_{i j} w_{i}}{\phi}\right)^{1-\sigma}}{P_{j}^{1-\sigma}}}_{\begin{array}{c}
\text { intensive margin of } \\
\text { sales per consumer }
\end{array}} .
$$

In the fixed cost model, firms choose $n_{i j}(\phi)=1 \forall \phi \geq \phi_{i j}^{*}$, and thus their sales inherit the shape of the intensive margin which is of the standard CES Dixit-Stiglitz form. A percentage change in the productivity of the firm implies a proportionate change in its sales. The sales in the intensive margin - even for firms with $\phi=\phi_{i j}^{*}$ - begin at a positive threshold as can be seen in figure 4. However, in the endogenous cost model, the simple addition of increasing marginal

\footnotetext{
${ }^{18}$ The exact form of $\lambda_{i j}$ will be given later on. For an in-depth analysis of the derivation of the labor market equilibrium in models with heterogeneous firms, see Eaton and Kortum (2005).

${ }^{19}$ In addition, this assumption allows the model to match the empirically observed distribution of the sales of firms (Axtell (2001)). See Kortum (1997), Eaton, Kortum, and Kramarz (2005), Gabaix (1999), Luttmer (2006), and Arkolakis (2007) for justifications of using this distribution of productivities.
} 
costs to reach additional consumers introduces a new margin in the firm's sales: the extensive margin of consumers. While high productivity firms reach almost all consumers, low productivity ones have small sales per consumer and also choose to reach a small fraction of the consumers, which could be arbitrarily close to zero as seen in figure 3 . If the marginal cost function for market penetration has increasing elasticity, a feature that the functional form (5) with $\beta>0$ is endowed with, the changes in the extensive margin will become proportionately smaller for firms with larger productivities. The mechanics of the extensive margin will be key for accounting for observations in the trade data.

Finally, substituting for the equilibrium conditions, the sales of a firm with productivity $\phi$ from source country $i$ selling to country $j$ can be expressed as:

$$
r_{i j}(\phi)=\left\{\begin{array}{lc}
L_{j}^{\alpha} y_{j}^{\gamma} y_{i}^{1-\gamma} \frac{1}{\tilde{\psi}}\left[\left(\frac{\phi}{\phi_{i j}^{*}}\right)^{\sigma-1}-\left(\frac{\phi}{\phi_{i j}^{*}}\right)^{(\sigma-1) / \tilde{\beta}}\right] & \text { if } \phi \geq \phi_{i j}^{*} \\
0 & \text { otherwise. }
\end{array}\right.
$$

where

$$
\tilde{\theta}=\frac{\theta}{\sigma-1}, \tilde{\beta}=\frac{\beta}{\beta-1}, \tilde{\psi}=\frac{\psi}{\sigma(1-\eta)}
$$

and $\eta=(\sigma-1) /(\theta \sigma)$ is the share of profits out of total income (see appendix B). Observe that the case of Melitz (2003) and Chaney (2007) emerges by setting $\alpha, \gamma=0$ and taking $\beta \rightarrow 0$ :

$$
r_{i j}(\phi)= \begin{cases}y_{i} \frac{1}{\tilde{\psi}}\left(\frac{\phi}{\phi_{i j}^{*}}\right)^{\sigma-1} & \text { if } \phi \geq \phi_{i j}^{*} \\ 0 & \text { otherwise }\end{cases}
$$

with the parameter $1 / \psi$ incorporated in the term $1 / \tilde{\psi}$ being the corresponding fixed cost of exporting. ${ }^{20}$

\section{Calibration}

The model is particularly simple to calibrate by assuming a particular distribution of productivities of firms and then following a methodology similar to the one developed by EKK05. The

\footnotetext{
${ }^{20}$ Chaney (2007) solves the model with $\beta=0$ allowing for market specific fixed costs $1 / \psi_{i j}$.
} 
parameters of the model can be calibrated directly by looking at 1) the relationship between the number of firms selling to at least some given number of markets and the sales of these firms in France and 2) the relationship between the number of French entrants per country, and the population and income per capita of that country.

\subsection{Parameters determining the relative sales of firms}

I will consider the sales of French firms in France as a function of the number of other countries

they serve. I denote by $M_{F F}^{(k)}$ the measure of French firms selling to France and to at least $k$ additional countries. These firms' total sales in France, $T_{F F}^{(k)}$, are given by the following expressions (see appendix D)

$$
\begin{gathered}
\beta=0: T_{F F}^{(k)}=M_{F F}^{(0)} L_{F}^{\alpha} y_{F} \frac{1}{\tilde{\psi}} \frac{\left(\frac{M_{F F}^{(k)}}{M_{F F}^{(0)}}\right)^{1-1 / \tilde{\theta}}}{1-1 / \tilde{\theta}}, \\
\beta>0: T_{F F}^{(k)}=M_{F F}^{(0)} L_{F}^{\alpha} y_{F} \frac{1}{\tilde{\psi}}\left[\frac{\left(\frac{M_{F F}^{(k)}}{M_{F F}^{(0)}}\right)^{1-1 / \tilde{\theta}}}{1-1 / \tilde{\theta}}-\frac{\left(\frac{M_{F F}^{(k)}}{M_{F F}^{(0)}}\right)^{1-1 /(\tilde{\theta} \tilde{\beta})}}{1-1 /(\tilde{\theta} \tilde{\beta})}\right] .
\end{gathered}
$$

In the model $\tilde{\theta}$ determines the sales advantage of more productive firms in the intensive margin of per consumer sales. The parameter $\beta$, that regulates adjustments in the extensive margin of consumers, governs the ability of firms to reach a larger fraction of the consumers in a market given that they enter that market.

Figure 6 plots the logarithm of total sales of French firms in France as a function of the number of firms selling to $k$ or more countries. The relationship suggests a slope of 0.35 indicating that firms that export to more markets sell also on average more in France. The slope of 0.35 implies an approximate value of $\tilde{\theta}$ of 1.5 for the model with $\beta=0$ (more details are given in appendix D). However, the fixed cost model overpredicts (by around 77\%) the total sales of all French firms. Given the parameter $\tilde{\theta}=1.5$, the model with $\beta=1$ delivers a better fit to the relationship in the right tail as depicted in figure 6. The reason for the better fit of the endogenous cost model is that firms that sell to only a few destinations are not only the least productive ones, but also choose to reach only a few consumers in France, that is, $n_{F F}(\phi)$ is close to 0 . When 
one accounts for these firms, the total sales in France increase much slower as a function of the number of destinations served than the simple fixed cost model would predict. The results of the above analysis suggest a $\beta$ closer to 1 rather than to 0 . Thus, I choose the value of $\beta=1$ as a benchmark value for the endogenous cost model throughout the remainder of my analysis.

\subsection{Parameters determining total exports and number of exporters}

The use of the Pareto distribution allows for analytical expressions for the fraction of spending by country $j$ on goods from country $i$,

$$
\lambda_{i j}=\frac{\left(\tau_{i j}\right)^{-\theta}\left(b_{i}\right)^{\theta} w_{i}^{(1-\gamma)(1-\tilde{\theta})-\theta}}{\sum_{v=1}^{N}\left(\tau_{v j}\right)^{-\theta}\left(b_{v}\right)^{\theta} w_{v}^{(1-\gamma)(1-\tilde{\theta})-\theta}}
$$

where the $\lambda_{i j}$ is a function of trade barriers $\tau_{i j}$, the technology $b_{i}$, and the wages $w_{i}$ of the countries. ${ }^{21}$ Notice that this expression is comparable to the one used by Eaton and Kortum (2002) in their estimation of the parameter that governs the extent of heterogeneity in the productivities of firms, $\theta$. I will use their estimate and set $\theta=8 .{ }^{22}$ Notice that given $\theta=8$, the estimation of $\tilde{\theta}=1.5$ implies $\sigma=6.33 .^{23}$

To calibrate the remaining parameters, $\alpha$ and $\gamma$, I begin by expressing the total export sales of French firms $(F)$ to country $j$ as:

$$
T_{F j}=\lambda_{F j} L_{j} y_{j}
$$

Alternatively, I can express export sales as the measure of exporting firms times average export

\footnotetext{
${ }^{21}$ For simplicity, I set $J_{i}=J$.

${ }^{22}$ Eaton and Kortum (2002) use data on bilateral trade shares, prices, and distance as a proxy for trade costs for a cross section of countries. Their estimation corresponds to estimating the parameter governing the elasticity of substitution between goods for models with the Armington aggregator. Romalis (2005) estimates the later elasticities using data on trade and tariffs studying the countries that joined the NAFTA. He finds parameter values for the elasticity of substitution in the range of 6.2 to 10.9 , which are consistent with the estimate of Eaton and Kortum.

${ }^{23}$ The value of $\sigma=6.33$ is higher than values used in the business cycles literature (around 2) or values previously estimated using models of trade with heterogeneous firms (e.g. Bernard, Eaton, Jensen, and Kortum (2003) report that $\sigma=3.79$ is the value that allows their model to match the sales advantage of exporters in the US data). However, the value of $\sigma=6.33$ yields a mark-up of around 1.2, which is consistent with mark-ups reported in the data (see Martins, Scarpetta, and Pilat (1996)).
} 
sales per firm:

$$
T_{F j}=M_{F j} \underbrace{L_{j}^{\alpha} y_{j}^{\gamma} y_{F}^{1-\gamma} \frac{1}{\tilde{\psi}}\left(\frac{1}{1-1 / \tilde{\theta}}-\frac{1}{1-1 /(\tilde{\theta} \tilde{\beta})}\right)}_{\text {average sales per firm }} .
$$

Combining the two expressions above, I obtain:

$$
\frac{M_{F j}}{\lambda_{F j}}=L_{j}^{1-\alpha} y_{j}^{1-\gamma}\left[\left(y_{F}\right)^{1-\gamma} \frac{1}{\tilde{\psi}}\left(\frac{1}{1-1 / \tilde{\theta}}-\frac{1}{1-1 /(\tilde{\theta} \tilde{\beta})}\right)\right]^{-1}
$$

Expression (23) relates the number of French firms exporting to country $j$, normalized by French market share in country $j$, to the population and output per capita of that country. In fact, this expression implies that higher entry of firms in a market is related to higher returns to scale with respect to population size for the marketing technology (lower $\alpha$ ) and lower fraction of marketing costs paid in terms of importing country's wages (lower $\gamma$ ). Therefore, by modeling a common marketing technology across all firms and making realistic assumptions related to this marketing technology (assumptions 2 and 3), the model is able to capture a robust finding of EKK05: the number of French firms in a market, normalized by French market share, increases with the size of the market with an elasticity less than one.

For my estimation I use data on French firm entry per market from EKK04 and EKK05, and on population and manufacturing absorption per capita (as a proxy for output per capita), which I describe in appendix E. Taking natural logarithms of expression (23) I run the following regression, indicating the data counterpart of the variables with the use of an upper bar (robust standard errors in parentheses)

$$
\ln \left(M_{F j} / \lambda_{F j}\right)=\underset{(.628)}{-2.74}+\underset{(.034)}{0.56} \ln \bar{L}_{j}+\underset{(.028)}{0.69} \ln \bar{y}_{j}
$$

The $R^{2}$ of the regression is .89 . The coefficients are less than one, as predicted by the theory. A formal econometric test rejects the hypothesis that these coefficients are the same at the $1 \%$ level, further supporting the validity of assumptions 2 and 3. The estimation implies that the cost to reach a given number of consumers decreases with an elasticity of .56 with the size of the population. It also suggests that around $1 / 3$ of the marketing costs to reach foreign consumers 
are paid in terms of the importing country's wages. The value of $\gamma=.31$ is different than the ones typically assumed in the literature i.e. $\gamma=0$-in terms of the exporting country's wages only- as in Ghironi and Melitz (2005) or $\gamma=1$-in terms of the importing country's wages onlyas is implicit in EKK05. Finally, I use the constant of the regression to determine $1 / \psi$ (see equation (22)).

\section{Market Penetration Costs and Puzzles in International Trade}

In this section I gauge the ability of the endogenous cost model to predict the export behavior of French firms and trade flows in the event of a trade liberalization episode using the mechanism of the extensive margin of consumers. Notice that throughout the rest of my analysis I keep the parameters of the model that was calibrated using the French data.

\subsection{The distribution of sales}

In figure $7 \mathrm{I}$ plot the sales distribution of French firms to Portugal, which is one of the 113 exporting markets studied by EKK05. The authors report that the characteristics of the sales distribution of French firms across markets are very robust. Thus, the choice of an average size exporting market, such as Portugal, is very representative. A noticeable feature of the sales distribution across markets is the large proportion of French firms selling to a particular market that sell small amounts in that market.

In the model, the sales of a firm with productivity $\phi$ from country $i$ to $j$ are given by equation (17). I define the smallest sales (revenues) of firms from country $i$ to $j$ as $r_{i j}^{\min }$. In the fixed cost model, the minimum sales in country $j$ that correspond to firms with productivity $\phi=\phi_{i j}^{*}$ are given by

$$
r_{i j}^{\min }=L_{j}^{\alpha} y_{j}^{\gamma} y_{i}^{1-\gamma} / \tilde{\psi}
$$

In the case of the endogenous cost model, when $\beta>0$, the minimum sales for firms with productivity $\phi=\phi_{i j}^{*}$ are

$$
r_{i j}^{\min }=0
$$


The distribution of sales, $\operatorname{Pr}\left[R<r \mid R \geq r_{i j}^{\min }\right]=F_{i j}(r)$, can be solved analytically for $\beta=0,1$ (see appendix C):

$$
\begin{gathered}
\beta=0: F_{i j}(r)=1-\left(\frac{r}{L_{j}^{\alpha} y_{j}^{\gamma} y_{i}^{1-\gamma} / \tilde{\psi}}\right)^{-\tilde{\theta}} r \geq r_{i j}^{\min }, \\
\beta=1: F_{i j}(r)=1-\left(\frac{r}{L_{j}^{\alpha} y_{j}^{\gamma} y_{i}^{1-\gamma} / \tilde{\psi}}+1\right)^{-\tilde{\theta}} r \geq r_{i j}^{\min } .
\end{gathered}
$$

In figure 7 , I show that the fixed cost model, parameterized to match the fact that most firms do not export, overpredicts the size of the smallest exporters ( $1^{\text {st }}$ percentile) by a factor of 150. Thus, the model also underpredicts the size of the largest exporters ( $99^{\text {th }}$ percentile) by a factor of around 1.7. However, the predictions of the endogenous cost model are closely aligned with the data. In particular, the model predicts the large number of small exporters -for the $1^{\text {st }}$ percentile it only overpredicts sales by a factor of 1.5- and improves upon the predictions of the fixed cost model across all percentiles.

The reason for the improved prediction of the endogenous cost model is the mechanism illustrated in section 2: firms with lower productivities not only sell less per consumer, but also to fewer consumers. The absense of indivisibilities in the marketing costs implies a small size for the low productivity firms. This fact combined with the increasing elasticity of the marginal market penetration cost function captures both the existence of small exporters and the curvature in the sales distribution of small exporters that EKK05 report. In terms of a sales distribution in a logarithmic scale, the model with $\beta=1$ would imply that the sales distribution in logarithms exhibits curvature for relatively small firms. However, it would still retain a linearity for the larger firms as is observed in the French data by each destination as well as in various other studies on domestic sales of firms (see Axtell (2001) and Luttmer (2006)). Summarizing, the model with the extensive margin of consumers, calibrated to match the size advantage in France of prolific exporters, is able to reproduce the sales distribution of French firms in each particular market. 


\subsection{Trade flows and bilateral trade liberalizations}

Using the parameters inferred from the size advantage in France of prolific exporters, I will subject the model to a further test by looking at its predictions in a trade liberalization episode. The analysis in this dimension is constrained from the unavailability of firm level data on the sales of exporting firms before and after a liberalization episode. Therefore, I will use the best available proxy which is very dissagregated goods data. I will also make use of the strict mapping that my model implies, meaning that each firm produces only one good. Thus, in the rest of this section I will treat each goods category as if it was produced by one firm.

I measure the increase in trade flows for the previously traded goods extending the methodology of Kehoe and Ruhl (2003). In particular, Kehoe and Ruhl study the contribution of least traded goods (including previously nontraded) to the total increase in trade after trade liberalization. Instead, I consider the particular contribution of the least traded goods, conditional on being positively traded before liberalization, to the total increase in trade after the liberalization.

In my analysis, I use data from the OECD International Trade by Commodity database (see appendix E for details) on US imports from Mexico recorded in 6-digit Harmonized System (HS) encoding. ${ }^{24}$ Below I construct a classification of the goods. I call the goods traded before the liberalization and throughout 1990-92 "previously traded" goods. I divide the "previously traded" goods in 10 categories with equal number of goods. These categories include goods in an increasing order of volume of trade: category 10 includes the "previously traded" goods that were on average most traded in 1990-92, while category 1 the least traded ones. The goods that were traded in 1997-99 (at least once in these three years) but not throughout all the years of 1990-92 are referred to as "newly traded" goods. I also divide the "newly traded" goods into two categories depending on whether they were continuously traded throughout 1997-99 (category 1) or traded in some of these years (category 2). Finally, I will refer to the goods that were traded in some of the years of 1990-92 but were not traded in 1997-99 as "newly nontraded" goods.

The OECD database provides information on US imports from Mexico for 5402 goods. 2298 of these goods were positively traded throughout 1990-92 and thus each category of "previously traded" goods consists of 230 goods (with category 10 consisting of 229 goods). The number of

\footnotetext{
${ }^{24}$ In general the reporting of import flows from importing countries is more accurate. The results of my analysis remain the same if I use reports on exports from Mexico by good category instead.
} 
"newly traded" goods is 1767 and 907 of these belong to category 1 of "newly traded" goods, while the remaining 860 constitute category 2 of the "newly traded" goods. Finally, the dataset contains 230 "newly nontraded" goods and 1107 goods that were never traded.

Table 1 provides information on the share of trade for each of the categories of traded goods defined in the previous paragraph. It reports the share out of total trade in 1990-92 and 199799. It also reports the contribution of each of the categories of "previously traded" and "newly traded" goods to new trade among these goods. In fact, as table 2 shows the share of the $15 \%$ least traded goods from the "previously traded" goods in 1990-92 increased to almost $25 \%$ amongst the same goods. A more clear pattern is depicted in figure 8 where I plot the natural logarithm of the ratio of imports from 1997-99 to imports from 1990-92 for each category of "previously traded" goods. The percentage increase of trade flows is higher the less tradable the good is in 1990-92. My analysis indicates that while "newly traded" goods are numerous, they also are of small trade volume on average. Thus, a large part of the new goods trade accounted by Kehoe and Ruhl (2003) can actually be interpreted as new trade of "previously traded" goods that were least traded before liberalization.

Kehoe (2005), in an evaluation of Applied General Equilibrium (AGE) models used to predict NAFTA, concludes that no plausible parameterization can make models based solely on the CES Dixit-Stiglitz specification match the trade flows after the NAFTA liberalization. He points out that this failure is exactly due to their inability to predict high growth in trade for goods with low volume of trade prior to the liberalization. The endogenous cost model features deviations from the CES demand structure that can account for the faster growth rates of trade for goods with little previous trade. In the endogenous cost model even a small decrease in variable trade costs that brings about a small increase in the marginal revenue per consumer makes a proportionately larger expansion of the consumer base of these goods profitable. ${ }^{25}$ The following proposition formalizes the above argument.

\footnotetext{
${ }^{25}$ In order to generate observationally equivalent results to the ones of the model presented here alternative explanations have to deviate from the assumptions of CES demand given the CRS production function. DRS in production is clearly an unrealistic assumption to the extend that it has to be assumed for the production of the firm to each destination. Alternative plausible explanations are non-CES forms of demand such as the one assumed by Melitz and Ottaviano (2007). Apart from the tight association to the data, the additional quantitative advantage of the approach I follow -for the set of question I address - is that my framework retains all the previous desirable properties of the Melitz-Chaney framework pointed out by EKK05 (e.g. the log-linear association between firm entry and market size)
} 


\section{Proposition 2}

Assume that all countries are symmetric with $\tau_{i i}=1 \forall i$ and $\tau_{i j}=\tau_{i v}>1 \forall j, v$, s.t. $j, v \neq i$. Define a symmetric trade liberalization as $\tau_{i i}^{\prime}=1 \forall i$ and $\tau_{i j}^{\prime} \forall i \neq j$ such that $\tau_{i j}>\tau_{i j}^{\prime} \geq 1 \forall i \neq j$, and $\tau_{i j}^{\prime}=\tau_{i v}^{\prime} \forall j, v$ s.t. $j, v \neq i$. Then:

The elasticity of trade flows of a good with respect to $\tau_{i j}, \forall i \neq j$, is higher the lower the productivity $\phi$ that the good is produced with, for all $\phi$ s.t. $\phi \geq \phi_{i j}^{*}$.

Proof. Normalize $w_{j}=1 \forall j=1, \ldots, N$. It can be shown that the new $\tau_{i j}^{\prime} i \neq j$, given $\tau_{i i}^{\prime}=1$, results in a decrease of $\phi_{i j}^{*} \forall i \neq j$. The exact elasticity of trade flows depends on the model's parameters and initial level of $\tau_{i j} \forall i, j$. It is, therefore, sufficient to focus our analysis on the effect of a decrease in $\phi_{i j}^{*}$ to trade flows $r_{i j}(\phi)$. Rewriting (17) and using the normalization $w_{i}=1, \forall i$ :

$$
r_{i j}(\phi)=\underbrace{L_{j}^{\alpha} \frac{\sigma}{\psi}\left(\frac{\phi}{\phi_{i j}^{*}}\right)^{\sigma-1}}_{\begin{array}{c}
\text { intensive margin } \\
\text { of sales per } \\
\text { consumer }
\end{array}} \underbrace{\left(1-\left(\frac{\phi_{i j}^{*}}{\phi}\right)^{(\sigma-1) / \beta}\right)}_{\begin{array}{c}
\text { extensive margin of } \\
\text { consumers }
\end{array}}, \phi \geq \phi_{i j}^{*}, i \neq j .
$$

The objective is to compute the elasticity of trade flows with respect to a change in $\phi_{i j}^{*}$, namely $\zeta=-d \ln r_{i j}(\phi) / d \ln \phi_{i j}^{*}$. This elasticity is higher for low initial productivity $\phi,{ }^{26}$

$$
\zeta=\underbrace{(\sigma-1)}_{\begin{array}{c}
\text { intensive margin } \\
\text { of sales per } \\
\text { consumer elasticity }
\end{array}}+\underbrace{\frac{\sigma-1}{\beta}\left[\left(\frac{\phi}{\phi_{i j}^{*}}\right)^{(\sigma-1) / \beta}-1\right]^{-1}}_{\begin{array}{c}
\text { extensive margin of } \\
\text { consumers elasticity }
\end{array}} .
$$

Notice that $\zeta=\zeta(\phi)$ and is decreasing in $\phi$ and thus decreasing in initial export sales. In fact, as $\beta \rightarrow 0, \zeta(\phi) \rightarrow(\sigma-1) \forall \phi \geq \phi_{i j}^{*}$.

To quantitatively assess the ability of the models to match the patterns of trade flows after trade liberalizations I choose the reduction in variable trade costs so that the two models match the total growth in the trade in "previously traded" goods. The fixed cost model requires a $12.5 \%$ decrease in variable trade costs, while the endogenous cost requires only a $9.5 \%$ decrease (further details are given in appendix E). In figure 8, I plot the two models' predicted increase in growth

\footnotetext{
${ }^{26}$ Since the general equilibrium effect is the same across goods I set for simplicity $\partial \ln \phi_{i j}^{*} / \partial \ln \tau_{i j}=1$.
} 
for each category of "previously traded" goods along with the actual data. The endogenous cost model delivers a close match to the data, while the fixed cost model falls short of predicting the empirical pattern.

The interaction between the extensive margin of consumers and CES preferences allows the endogenous cost model to successfully replicate the increase in trade flows after the introduction of NAFTA, providing a solution of the puzzle reported by Kehoe (2005). In the next section, I analyze the role the new consumers margin plays in international trade through its contribution in new trade flows after a trade liberalization.

\section{How important is the new consumers margin in inter- national trade?}

In the above analysis I have introduced a new margin of adjustment in export sales, namely the extensive margin of consumers of each firm. Aside from the semantics, the new margin is capturing the faster growth of smaller firms, which is an implication of the deviation from the CES demand structure. To evaluate the importance of the growth of small firms during a trade liberalization episode, I proceed to decompose the three margins of adjustment of aggregate trade flows that the model features in the event of a trade liberalization:

i) Intensive margin growth (total growth in sales per consumer)

ii) The new consumers margin (total growth in the extensive margin of consumers)

iii) The new firms margin (total growth in the extensive margin of firms)

I refer to the extensive margin of firms as the number of firms exporting. The intensive margin of sales per consumer is the sales of the firm to each consumer that the firm reaches in a market. Essentially, previous literature referred to the intensive margin in what I refer to here as the extensive margin of consumers multiplied by what I have defined as the intensive margin of sales per consumer. In the endogenous cost model, as a source country becomes more expensive each firm of this country exports to a narrower set of consumers. In contrast, in models with adjustments mainly in the extensive margin of firms, more expensive countries mainly export in 
a narrower set of goods (as in Eaton and Kortum (2002)). ${ }^{27}$ Finally, in models with monopolistic competition but homogeneous firms, as in Krugman (1980), the only adjustment is through the intensive margin of sales per consumer.

In recent years an increased amount of attention has been given to the new firms margin. This attention stems partly from the ability of models that have this margin of adjustment to exhibit large increases in trade with small decreases in trade costs, without assuming unrealistically high elasticities of substitution. ${ }^{28}$ The elasticity of trade flows with respect to changes in variable trade costs is $\theta$ both for the endogenous and the fixed cost model. However, when decomposing the importance of each of the margins, as shown in the next proposition, the contribution of the new firms margin is minimal (at least for small reductions in the variable trade costs). The following proposition formalizes the above discussion.

\section{Proposition 3}

i) The elasticity of trade flows with respect to variable trade costs $\tau_{i j}$ is $\theta$.

ii) For small changes in variable trade costs $\tau_{i j}$, changes in the new consumers margin always dominate the changes in the new firms margin.

Proof. Both parts of the proof will be shown by performing a decomposition using the Leibniz rule to separate the three margins. We have that total export sales of country $i$ to $j$ are:

$$
T_{i j}=J \int_{\phi_{i j}^{*}}^{\infty} n_{i j}(\phi) x_{i j}(\phi) g_{i}(\phi) d \phi
$$

The change in total export sales of country $i$ to country $j$ due to a change in variable trade costs is given by (following methodology similar to Chaney (2007)):

$$
\frac{d T_{i j}}{d \tau_{i j}}=\underbrace{J \int_{\phi_{i j}^{*}}^{\infty} n_{i j}(\phi) \frac{\partial x_{i j}(\phi)}{\partial \tau_{i j}} g_{i}(\phi) d \phi}_{\text {Intensive margin growth }}+\underbrace{J \int_{\phi_{i j}^{*}}^{\infty} \frac{\partial n_{i j}(\phi)}{\partial \tau_{i j}} x_{i j}(\phi) g_{i}(\phi) d \phi}_{\text {New consumers margin }}+
$$

\footnotetext{
${ }^{27}$ Evidence on the existence of an extensive margin of goods and firms in international trade is provided by Hummels and Klenow (2005) and EKK05 respectively.

${ }^{28} \mathrm{Ruhl}$ (2005), using a model with adjustment in the extensive margin of firms, proposes a solution to the so-called elasticity puzzle, namely the contrast of the low elasticity needed to explain the patterns of international business cycles with the high elasticity needed to explain the growth of trade following reductions in trade costs.
} 


$$
+\underbrace{J n_{i j}\left(\phi_{i j}^{*}\right) x_{i j}\left(\phi_{i j}^{*}\right) g_{i}\left(\phi_{i j}^{*}\right) \frac{\partial \phi_{i j}^{*}}{\partial \tau_{i j}}}_{\text {New firms margin }} .
$$

I rewrite this decomposition in terms of elasticities:

$$
\frac{d \ln T_{i j}}{d \ln \tau_{i j}}=-\underbrace{(\sigma-1)}_{\begin{array}{c}
\text { Intensive margin } \\
\text { growth elasticity }
\end{array}}-\underbrace{(\theta-\sigma+1)}_{\begin{array}{c}
\text { New consumers } \\
\text { margin elasticity }
\end{array}}+\underbrace{0}_{\begin{array}{c}
\text { New firms } \\
\text { margin elasticity }
\end{array}}
$$

First, notice that $d \ln T_{i j} / d \ln \tau_{i j}=-\theta$, proving part i). For part ii), given the assumption $\theta>\sigma-1$ that is required for the integrals to converge, small decreases in variable trade costs cause a substantial increase in trade flows attributed to the new consumers margin. The corresponding contribution of the new firms margin is tiny. This can be verified from the expression that represents the part of the derivative related to the new firms margin: because the extensive margin of consumers is close to 0 for small firms $\left(n_{i j}\left(\phi_{i j}^{*}\right)=0\right)$, any small change in the trade costs that causes new firms to trade $\left(\partial \phi_{i j}^{*} / \partial \tau_{i j}\right)$ has minimal contribution in the increase in total export sales.

To provide further intuition of the above result I look at the comparative statics of trade liberalization and in particular I look at the density of exports for firms with different productivities before and after a trade liberalization. Figure 9 graphs the density of exports for each level of productivity (total amount exported by firms of the given productivity) for the endogenous cost and the fixed cost model, before the event of a trade liberalization. In the fixed cost model, the density of exports inherits the shape of the Pareto distribution of productivities given the CES demand specification. However, in the endogenous cost model, the extensive margin of consumers is small for firms with relatively low productivities, and thus the density of sales is hump-shaped. Thus, deviations from the CES demand for the small firms imply that the contribution of these firms is minor in total export sales. In addition, in figure 10, I graph the predictions of the models for the three margins' contribution to the change in aggregate trade flows for the calibrated US-Mexico trade liberalization episode with a $9.5 \%$ decrease in trade costs. Consistent with what the theory predicts, relatively small trade cost changes will imply that adjustments in the new consumers margin will be substantially larger for firms with small 
(but positive) numbers of consumers before the trade liberalization. The quantitative decomposition of new trade in the event of a trade liberalization using the model with $\beta=1$ implies that the percent contribution to new trade of the intensive margin growth, the new firms margin, and the new consumers margin is $56.9 \%, 14.7 \%$, and $28.4 \%$, respectively. In contrast, the fixed cost model would predict that the percent contribution to new trade of the intensive margin growth and the new firms margin is $56.9 \%$ and $43.1 \%$, respectively. Thus, my model implies that up to $28.4 \%$ of new trade was not correctly accounted for by previous theory.

\section{Conclusion}

In this paper, I develop a theory of marketing costs that provides a deeper understanding of the barriers individual firms face when selling to foreign markets. This theory provides a formulation of market penetration costs on the basis that additional marketing efforts in a market lead to increases in the sales of the firm there, but at a decreasing rate. I model this margin of adjustment as the extensive margin of firms' consumers. Incorporated in the workhorse monopolistic competition trade framework with product differentiation and firm productivity heterogeneity, the interaction of this formulation with the CES demand can account for a number of key observations in trade data. These observations seemed particularly puzzling in the view of models with a uniform fixed cost of exporting.

The introduction of the new margin of adjustment of firms' sales -the new consumers marginis capturing the large amount of small exporters we observe in each market. Still, as Arkolakis and Muendler (2007) show, this explanation is consistent with the introduction of an additional extensive margin in the sales of the firms, the one of more goods. Additionaly, the tractability of the new framework makes it applicable for a variety of new applications. In fact, Arkolakis (2007) shows that this framework is consistent with a set of new dynamic facts on firms and exporters documented by Eaton, Eslava, Kugler, and Tybout (2008).

An important new prediction of the model is that a significant amount of new trade in the event of trade liberalization comes from previously small, rather than new, exporters. This prediction comes in sharp contrast to the previous theory's findings, which emphasize the importance of new firms for the overall increase in trade after a liberalization. With the increasing 
availability of firm-level data, future research can shed light on the empirical validity of the different theories. The parsimonious formulation I develop omits many important features of the world. However, the new theory has taken important steps toward understanding the role that market penetration costs can play in the context of a macroeconomic trade model. 


\section{References}

Arkolakis, C. (2007): "Market Penetration Costs and Trade Dynamics," mimeo, Yale University.

Arkolakis, C., S. Demidova, P. J. Klenow, and A. Rodriguez-Clare (2008): "Endogenous Variety and the Gains from Trade," forth., American Economic Review Papers and Proceedings.

Arkolakis, C., And M.-A. Muendler (2007): "The Extensive Margin of Exporting Goods: A Firm Level Analysis," mimeo, University of California San Diego and Yale University.

Arndt, J., And J. L. Simon (1983): "Advertising and Economies of Scale: Critical Comments on the Evidence," The Journal of Industrial Economics, 23(2), 229-241.

Aw, B. Y., S. Chung, And M. J. Roberts (2000): "Productivity and Turnover in the Export Market: Micro Level Evidence from the Republic of Korea and Taiwan (China)," The World Bank Economic Review, 14(1), 65-90.

Axtell, R. L. (2001): "Zipf Distribution of U.S. Firm Sizes," Science, 293(5536), 1818-1820.

BAgwell, K. (2007): "The Economic Analysis of Advertising," in Handbook of Industrial Organization, ed. by M. Armstrong, and R. Porter, vol. 3, pp. 1701-1844. North-Holland, Amsterdam.

Bernard, A. B., J. Eaton, B. Jensen, and S. Kortum (2003): "Plants and Productivity in International Trade," The American Economic Review, 93(4), 1268-1290.

Bernard, A. B., and J. B. Jensen (1995): "Exporters, Jobs, and Wages in U.S. Manufucturing: 1976-1987," Brooking Papers: Microeconomics, pp. 67-119.

Butters, G. (1977): "Equilibrium Distributions of Sales and Advertising Prices," The Review of Economic Studies, 44(3), 465-491.

Chaney, T. (2007): "Distorted Gravity: The Intensive and the Extensive Margins of International Trade," mimeo, University of Chicago. 
Clerides, S. K., S. Lach, and J. R. Tybout (1998): "Is Learning by Exporting Important? Micro-Dynamic Evidence from Colombia, Mexico, and Morocco," Quarterly Journal of Economics, pp. 903-947.

Das, S., M. J. Roberts, and J. R. Tybout (2005): "Market Entry Costs, Producer Heterogeneity, and Export Dynamics," NBER Working Paper, 8629.

Dinlersoz, E. M., and M. Yorukoglu (2006): "Informative Advertising by Heterogeneous Firms," mimeo, University of Houston.

Eaton, J., M. Eslava, M. Kugler, and J. Tybout (2008): “The Margins of Entry Into Export Markets: Evidence from Colombia," in The Organization of Firms in a Global Economy, ed. by E. Helpman, D. Marin, and T. Verdier. (forth.) Harvard University Press, Massachusets.

Eaton, J., And S. Kortum (2002): “Technology, Geography and Trade," Econometrica, 70(5), 1741-1779.

(2005): Technology in the Global Economy: A Framework for Quantitative Analysis. mimeo, University of Minnesota.

Eaton, J., S. Kortum, and F. Kramarz (2004): "Dissecting Trade: Firms, Industries, and Export Destinations," The American Economic Review, Papers and Proceedings, 94(2), 150154.

— (2005): "An Anatomy of International Trade: Evidence from French Firms," mimeo, University of Minnesota and New York University.

Farris, P. W., and R. D. Buzzell (1979): "Why Advertising and Promotional Costs Vary: Some Cross-Sectional Analyses," Journal of Marketing, 43(4), 112-122.

Gabaix, X. (1999): "Zipf's Law for Cities: An Explanation," Quarterly Journal of Economics, 114(3), 739-767.

Ghironi, F., And M. Melitz (2005): "International Trade and Macroeconomic Dynamics with Heterogeneous Firms," Quarterly Journal of Economics, 120(3), 865-915. 
Grossman, G. M., and C. Shapiro (1984): "Informative Advertising with Differentiated Products," The Review of Economic Studies, 51(1), 63-81.

Helpman, E., M. J. Melitz, and S. R. Yeaple (2004): "Export Versus FDI with Heterogeneous Firms," The American Economic Review, 94(1), 300-316.

Hopenhayn, H. A. (1992): "Entry, Exit, and Firm Dynamics in Long Run Equilibrium," Econometrica, 60(5), 1127-1150.

Hummels, D., and P. Klenow (2005): "The Variety and Quality of a Nation's Exports," The American Economic Review, 95(3), 704-723.

Jones, J. P. (1995): New Proof That Advertising Triggers Sales. Lexington Books, New York.

Keesing, D. B. (1983): "Linking Up to Distant Markets: South to North Exports of Manufactured Consumer Goods," The American Economic Review, 73(2), 338-342.

Kenoe, T. J. (2005): "An Evaluation of the Performance of Applied General Equilibrium Models of the Impact of NAFTA," in Frontiers in Applied General Equilibrium Modeling, ed. by T. J. Kehoe, T. Srinivasan, and J. Whalley, pp. 341-377. Cambridge University Press, New York.

Kehoe, T. J., and K. J. Ruhl (2003): "How Important is the New Goods Margin in International Trade," Federal Reserve Bank of Minneapolis, Staff Report, 324.

Kortum, S. (1997): "Research, Patenting, and Technological Change," Econometrica, 65(6), $1389-1419$.

Krugman, P. (1980): "Scale Economies, Product Differentiation, and the Pattern of Trade," The American Economic Review, 70(5), 950-959.

Lambin, J. J. (1976): Advertising, Competition and Market Conduct in Oligopoly over Time. An Econometric Investigation in Western European Countries. North Holland, Amsterdam.

Luttmer, E. G. (2006): "Selection, Growth, and the Size Distribution of Firms," forth., Quarterly Journal of Economics. 
Martins, J. O., S. Scarpetta, and D. Pilat (1996): "Mark-Up Ratios in Manufacturing Industries: Estimates for 14 OECD Countries," OECD Economics Department Working Paper, 162.

Melitz, M., and G. Ottaviano (2007): "Market Size, Trade, and Productivity," forthcoming, Review of Economics Studies.

Melitz, M. J. (2003): "The Impact of Trade on Intra-Industry Reallocations and Aggregate Industry Productivity," Econometrica, 71(6), 1695-1725.

Roberts, M. J., And J. R. Tybout (1997): What Makes Exports Boom? The World Bank, Washington, D.C.

Romalis, J. (2005): “NAFTA's and CUFTA's Impact on International Trade," NBER Working Paper, 11059.

Ruhl, K. J. (2005): "The Elasticity Puzzle in International Economics," mimeo, University of Texas at Austin.

Saunders, J. (1987): "The Specification of Aggregate Market Models," European Journal of Marketing, 21(2), 5-47.

Simon, J. L., And J. ARndt (1980): "The Shape of The Advertising Response Function," Journal of Advertising Research, 20(4), 767-784.

Stegeman, M. (1991): "Advertising in Competitive Markets," The American Economic Review, 81(1), 210-223.

Sutton, J. (1991): Sunk Costs and Market Structure. The MIT Press, Massachusetts.

Thomas, L. G. (1989): "Advertising in Consumer Goods Industries: Durability, Economies of Scale, and Heterogeneity," Journal of Law and Economics, 32, 163-193.

Tybout, J. R. (2001): "Plant -and Firm- Level Evidence on "New" Trade Theories," NBER Working Paper, 8418. 
Uhlig, H. (1996): "A Law of Large Numbers for Large Economies," Economic Theory, 8(1), $41-50$. 


\section{Appendix}

\section{Appendix A: the maximization problem of the firm}

First, notice that for the case where $\beta>0$ the market penetration cost function inherits an

interiority condition when $n \rightarrow 1$ since $\lim _{n \rightarrow 1} \frac{1-(1-n)^{-\beta+1}}{-\beta+1}=+\infty$. Therefore, when solving for the maximization problem of the firm, that is given in the main text, I need only consider the restriction $n \geq 0$.

Rewriting the problem of a type $\phi$ firm in a Langrangian formulation with the additional constraint that $n \geq 0$ :

$$
\mathcal{L}(\phi)=n L y \frac{p^{1-\sigma}}{P^{1-\sigma}}-n L y \frac{p^{-\sigma} w}{P^{1-\sigma} \phi}-w \frac{L^{\alpha}}{\psi} \frac{1-(1-n)^{-\beta+1}}{-\beta+1}+\lambda n
$$

FOC with respect to $p$ :

$$
p(\phi)=\tilde{\sigma} \frac{w}{\phi}
$$

FOC with respect to $n$ :

$$
L y \frac{p(\phi)^{1-\sigma}}{P^{1-\sigma}}-L y \frac{p(\phi)^{-\sigma} w}{P^{1-\sigma} \phi}-w \frac{L^{\alpha}}{\psi}[1-n(\phi)]^{-\beta}+\lambda=0
$$

and $\lambda n(\phi)=0, \lambda \geq 0$.

Using equation (28), (29) becomes

$$
\frac{y}{\sigma} \frac{\left(\tilde{\sigma} \frac{w}{\phi}\right)^{1-\sigma}}{P^{1-\sigma}}-\frac{w L^{\alpha-1}}{\psi}[1-n(\phi)]^{-\beta-1}+\lambda=0 .
$$

Notice that there exists $\phi^{*}$, s.t. $\forall \phi \leq \phi^{*}$ this equation holds only for some $\lambda>0 \Longrightarrow$ $n(\phi)=0$ (the constraint $n(\phi) \geq 0$ is binding). However, $\forall \phi>\phi^{*}$ the constraint is not binding and the corresponding $n(\phi) \in(0,1)$ is actually the solution to the above equation for $\lambda=0$. Thus, for $\phi \leq \phi^{*}, n(\phi)=0$. For all $\phi>\phi^{*}$, the optimal $n(\phi)$ is given by the solving equation (9).

I also check the second order conditions in order to derive sufficient conditions for this problem to have a unique solution for $n(\phi) \in[0,1]$. Evaluating the first and second principle submatrices 
of the Hessian matrix,

$$
A=\left[\begin{array}{cc}
\frac{\partial^{2} h}{\partial p^{2}} & \frac{\partial^{2} h}{\partial p \partial n} \\
\frac{\partial^{2} h}{\partial n \partial p} & \frac{\partial^{2} h}{\partial n^{2}}
\end{array}\right]
$$

results in the following derivations (notice that $\forall \phi>\phi^{*} n(\phi) \in(0,1)$ ):

$$
\begin{aligned}
& \frac{\partial^{2} h}{\partial p^{2}}=-\sigma(1-\sigma) n(\phi) L y \frac{p(\phi)^{-\sigma-1}}{P^{1-\sigma}}+(-\sigma-1) \sigma n(\phi) L y \frac{p(\phi)^{-\sigma-2}}{P^{1-\sigma} \phi}<0, \\
& \frac{\partial^{2} h}{\partial n^{2}}=(-\beta-1) w \frac{L^{\alpha}}{\psi} \frac{1}{[1-n(\phi)]^{\beta+1}}<0 \text { only if } \beta>0, \\
& \frac{\partial^{2} h}{\partial n \partial p}=\frac{\partial^{2} h}{\partial p \partial n}=(1-\sigma) L y \frac{p(\phi)^{-\sigma}}{P^{1-\sigma}}+\sigma L y \frac{p(\phi)^{-\sigma-1}}{P^{1-\sigma} \phi}=0 .
\end{aligned}
$$

Therefore, the principle submatrices satisfy $\left|A_{1}\right|<0,\left|A_{2}\right|>0$.

Since the second order condition holds, the unique pair $(n(\phi), p(\phi))$ that solves the equations (28) and (29), for a given $\phi>\phi^{*}$, is the unique maximum solving the firm's optimization problem (given the effective price index $P$ ). Therefore, the above formulation gives $n(\phi)$ as the solution of equation (29) $\forall \phi>\phi^{*}$. In addition, for $\phi \leq \phi^{*}, n(\phi)=0$.

\section{Appendix B: the share of profits}

In this appendix, I will show that the share of profits out of total income is constant and equal to $\eta=(\sigma-1) /(\theta \sigma) .{ }^{29}$ Notice that sales in $j$ for a firm with productivity $\phi$ from country $i$ are given by (17). Total export sales in $j$ from firms originating in country $i$ are given by expression (22). The total variable profit from production is simply $T_{i j} / \sigma$ and thus labor income from production is $T_{i j}(\sigma-1) / \sigma$. Total market penetration costs are

$$
m_{i j}=M_{i j} \int_{\phi_{i j}^{*}}^{\infty} L_{j}^{\alpha} w_{j}^{\gamma} w_{i}^{1-\gamma} \frac{1}{\psi} \frac{1-\left[1-n_{i j}(\phi)\right]^{-\beta+1}}{-\beta+1} \frac{\theta\left(\phi_{i j}^{*}\right)^{\theta}}{\phi^{\theta+1}} d \phi=T_{i j} \frac{[\theta-(\sigma-1)]}{\theta \sigma}
$$

Total labor income of country $i$ from the bilateral trade relationship with country $j$ equals income from production of goods and market penetration costs:

$$
w_{i j} L_{i j}=(\sigma-1) T_{i j} / \sigma+(1-\gamma) T_{i j}[\theta-(\sigma-1)] /(\theta \sigma)+\gamma T_{j i}[\theta-(\sigma-1)] /(\theta \sigma)
$$

Summing over all $j$ and using:

\footnotetext{
${ }^{29}$ For more details, see Eaton and Kortum (2005).
} 
a) equality of income and total expenditure $\sum_{j=1}^{N} T_{i j}=X_{i}$;

b) total labor income of country $i$ is the sum of labor incomes generated in order to produce and sell the good to all the $N$ countries $w_{i} L_{i}=\sum_{j=1}^{N} w_{i j} L_{i j}$;

c) trade balance condition, $\sum_{j=1}^{N} T_{i j}=\sum_{j=1}^{N} T_{j i}$,

we have that

$$
X_{i}=y_{i} L_{i}=w_{i} L_{i} /(1-\eta)
$$

Finally, given the above expression, trade balance also implies expression (16).

\section{Appendix C: sales' distribution}

I consider the case of sales of firms from country $i$ in market $j$. I proceed to represent the results as in EKK04 and EKK05 in order to compare the predictions of the model with the data they report.

Define by $r_{i j}^{\min }$ the sales for the firm with threshold productivity $\phi_{i j}^{*}$. The objective is to derive the distribution of sales denoted by $F_{i j}(r)$. Sales $r$, for firms with $\phi \geq \phi_{i j}^{*}$, are given by expression (17). Notice the following:

$$
\operatorname{Pr}\left[R \geq r \mid R \geq r_{i j}^{\min }\right]=\frac{\operatorname{Pr}[\Phi \geq \phi]}{\operatorname{Pr}\left[\Phi \geq \phi_{i j}^{*}\right]}=\frac{\left(\phi_{i j}^{*}\right)^{\theta}}{(\phi)^{\theta}}
$$

However, this can also be written as

$$
\operatorname{Pr}\left[R \geq r \mid R \geq r_{i j}^{\min }\right]=1-\operatorname{Pr}\left[R<r \mid R \geq r_{i j}^{\min }\right]=1-F_{i j}(r)
$$

which implies that

$$
1-F_{i j}(r)=\frac{\left(\phi_{i j}^{*}\right)^{\theta}}{(\phi)^{\theta}} .
$$

Replacing (30) into (17) obtains that sales for firms with $r \geq r_{i j}^{\min }$ are given by

$$
r=L_{j}^{\alpha} y_{j}^{\gamma} y_{i}^{1-\gamma} \frac{\sigma}{\tilde{\psi}}\left(\left[1-F_{i j}(r)\right]^{-1 / \tilde{\theta}}-\left[1-F_{i j}(r)\right]^{-1 /(\tilde{\theta} \tilde{\beta})}\right), \quad r \geq r_{i j}^{\min }
$$


For $\beta \rightarrow 0$, I can solve for the distribution of sales analytically and derive the expression (25). Therefore, in this case, the sales distribution is Pareto with coefficient $-1 / \tilde{\theta}$ as in EKK05 and Chaney (2007). However, the cases that I introduce emerge for $\beta>0$. I can solve for the sales distribution for some cases analytically. For example, when $\beta=1$, the distribution of sales is given by expression (26).

\section{Appendix D: calibration}

Parameters determining the relative sales of firms First, notice that in the model there is a strict hierarchy of destinations depending on $\phi_{i j}^{*}$, so that no firm is observed to sell to a less popular destination without selling to a more popular one. However, this prediction is not always observed in the data as EKK05 point out. Using entry shocks, EKK05 can generate patterns of entry that violate hierarchy. Their general setup can also be adapted in the context of my model.

Denote by $M_{i j}^{(k)}$ the measure of firms from country $i$ selling to country $j$, also selling to $k$ or more less popular markets. The probability that a firm from country $i$ selling in $j$ also sells to $k$ or more less popular markets is

$$
\frac{M_{i j}^{(k)}}{M_{i j}^{(0)}}
$$

Define the minimum productivity of a firm from $i$ selling to $j$ and at least $k$ more markets by $\phi_{i i}^{(k)}$. The probability of selling to at least $k$ markets conditional on selling in $j$ can also be written as

$$
\left(\frac{\phi_{i j}^{*}}{\phi_{i j}^{(k)}}\right)^{\theta}
$$

and thus,

$$
\frac{\phi_{i j}^{*}}{\phi_{i j}^{(k)}}=\left(\frac{M_{i j}^{(k)}}{M_{i j}^{(0)}}\right)^{\frac{1}{\theta}}
$$

Total sales in market $j$ of firms from market $i$ selling also to at least $k$ other destinations are equal to (exploiting the market hierarchy)

$$
T_{i j}^{(k)}=M_{i j}^{(k)} L_{j}^{\alpha} y_{j}^{\gamma} y_{i}^{1-\gamma} \frac{1}{\tilde{\psi}} \int_{\phi_{i j}^{(k)}}^{\infty}\left[\left(\frac{\phi}{\phi_{i j}^{*}}\right)^{\sigma-1}-\left(\frac{\phi}{\phi_{i j}^{*}}\right)^{(\sigma-1) / \tilde{\beta}}\right] \frac{\theta\left(\phi_{i j}^{(k)}\right)^{\theta}}{\phi^{\theta+1}} \Longrightarrow
$$




$$
T_{i j}^{(k)}=J_{i} \frac{b_{i}^{\theta}}{\left(\phi_{i j}^{*}\right)^{\theta}} L_{j}^{\alpha} y_{j}^{\gamma} y_{i}^{1-\gamma} \frac{1}{\tilde{\psi}}\left[\frac{1}{1-1 / \tilde{\theta}}\left(\frac{\phi_{i j}^{(k)}}{\phi_{i j}^{*}}\right)^{\sigma-1-\theta}-\frac{1}{1-1 /(\tilde{\theta} \tilde{\beta})}\left(\frac{\phi_{i j}^{(k)}}{\phi_{i j}^{*}}\right)^{(\sigma-1) / \tilde{\beta}-\theta}\right] .
$$

The last expression delivers expressions (18), (19) in the main text with the use of (31) and setting $i, j=F$.

Regarding the estimation of $\beta$ using the relationships derived above, an OLS regression of the natural logarithm of total sales in France on the natural logarithm of the number of firms selling to at least a given number of countries, yields a coefficient of 0.353 and constant of 13.42. This implies that $\tilde{\theta}$ is around 1.546 .

Parameters determining total exports and number of exporters The data on population are from the World Development Indicators of the World Bank. In the case of missing values I use data from Penn World Tables. Data on manufacturing absorption and share of French firms' sales in particular markets are taken from EKK04 (see their paper for details).

A regression of $\ln \bar{M}_{F j}$ on $\ln \bar{\lambda}_{F j}, \ln \bar{w}_{j}$ and $\ln \bar{L}_{j}$, will result to the following coefficients (robust standard errors in parentheses, I suppress the constant since it is of no interest):

$$
\ln \bar{M}_{F j}=\underset{(.030)}{0.87} \ln \bar{\lambda}_{F j}+\underset{(.028)}{0.52} \ln \bar{L}_{j}+\underset{(.025)}{0.67} \ln \bar{y}_{j}
$$

The $R^{2}$ is 0.913 and the coefficients on $\ln \bar{L}_{j}$ and $\ln \bar{y}_{j}$ are statistically significantly different from each other at the $1 \%$ level. The coefficient on $\ln \bar{\lambda}_{F j}$ is close to 1 , consistent to what is reported by EKK04, but not exactly 1 as my theory would imply. Thus, to be able to extract coefficients that are consistent with the overall analysis based on my model, I used the ones obtained from the regression reported in the text (which are the coefficients of running the regression reported in this note but restricting the coefficient of $\ln \bar{\lambda}_{F j}$ to be 1 ).

\section{Appendix E: data description}

Trade by goods data I use data from the OECD International Trade by Commodity database (www.sourceoecd.org) on imports by good of US from Mexico. ${ }^{30}$ The data are recorded using

\footnotetext{
${ }^{30} \mathrm{~A}$ similar pattern to the one I report for the Mexico-US case emerges for the Canada-Mexico trade liberalization episode.
} 
the Harmonized System (HS) 1988 revision (rev. 1) at the 6-digit level of detail and potentially can include up to 6873 different commodities (in the case of US imports from Mexico there is information on 5404 goods). Data on HS rev. 1 are available from 1990-2000. I only include data from 1990 to 1999 (10 years) due to inconsistency of the imports of US from Mexico reported by US and the exports of Mexico to US reported by Mexico, particularly for 2000 (note that the results do not change even if I include data for 2000). Also note that trade flows of the 6-digit level add up to aggregate trade flows from 1990-1995. From 1996, there is an average of 1\%-2\% of trade flows that are not recorded in the 6-digit trade flows. The reason is that the HS was revised in 1996 (rev. 2), and the data on trade flows from 1996 onward were initially reported according to the rev. 2 and then translated to the HS 1988 (rev. 1). In this reclassification, goods that could not be categorized back in rev. 1 were discarded. Even though some of the trade flows are missing at the 6-digit level, there is no observable persistent inconsistency that could lead to a mistaken interpretation of the data. Finally, I drop 2 categories of goods from my sample: special classification provisions (code 980100) and Intrastat estimation of missing declarations of chapter 99 (code 999900).

Grouping the goods First, I analyze in detail how I categorize the "previously traded" goods. I first look at the years 1990-92. I keep the goods being traded throughout all the years 1990-92. I group the goods that were traded in 1990-92 into ten categories, each with an equal number of goods. The categories include goods in increasing order of volume of trade during 1990-92 (e.g. category 1 contains the $10 \%$ least traded ones in 1990-92 while category 10 contains the $10 \%$ most traded goods). I compute the ratio of import sales of 1997-99 to 1990-92 for each category (essentially taking averages over 1990-92 and 1997-99). By considering only the goods that are traded throughout all years of 1990-92, I avoid including goods that are randomly or very rarely traded. With this adjustment I also avoid -to some extent- including new goods that tend to grow for some years after their introduction before reaching steady state levels and could create a bias towards higher growth of least traded goods. By allowing for goods that stopped being traded after 1992 to be in the sample I adjust towards selection of only surviving goods that would create higher growth rates for the least traded goods categories.

Related to the definition of "newly traded" goods, this definition is admittedly more favorable 
towards a higher importance of new goods in the event of a trade liberalization. On the other hand, the use of the dataset that provides information on goods rather than firms can create aggregation bias which will work against the importance of newly traded goods. Because of the unavailability of firm level data on trade liberalization episodes, data on goods in very fine categories of dissagregation, as the ones I use, is the best available substitute.

Mapping the model to the data In order to map the model to the data, I use the assumption of the theory that each good is produced by one firm. In the model I am considering the empirical counterpart of the relationship I computed in the data and thus I map each one of the 10 categories of the goods to $10 \%$ of the firms in an increasing order of volume of trade and productivity correspondingly. In particular, I consider the total sales of firms selling the goods that corresponds to each category. In fact, since I keep track of the same number of goods throughout time, I only have to compute the average sales of goods for each category. For the period before liberalization, average sales of each category in the model are given by

$$
\begin{gathered}
T_{i j}^{(k)}=L_{j}^{\alpha}\left(y_{j}\right)^{\gamma}\left(y_{i}\right)^{1-\gamma} \frac{1}{\tilde{\psi}} \int_{\phi_{i}}^{\phi_{i+1}}\left[\left(\frac{\phi}{\phi_{i j}^{*}}\right)^{\sigma-1}-\left(\frac{\phi}{\phi_{i j}^{*}}\right)^{(\sigma-1) / \tilde{\beta}}\right] \frac{\theta \phi_{i}^{\theta}}{\phi^{\theta+1}} d \phi \Longrightarrow \\
T_{i j}^{(k)}=L_{j}^{\alpha}\left(y_{j}\right)^{\gamma}\left(y_{i}\right)^{1-\gamma} \frac{1}{\tilde{\psi}}\left[\begin{array}{c}
\left(\frac{\phi_{i+1}}{\phi_{i j}^{*}}\right)^{\sigma-1} \frac{1}{1 / \tilde{\theta}-1} \frac{\phi_{i}^{\theta}}{\phi_{i+1}^{\theta}}-\left(\frac{\phi_{i+1}}{\phi_{i j}^{*}}\right)^{(\sigma-1) / \tilde{\beta}} \frac{1}{1 /(\tilde{\theta} \tilde{\beta})-1} \frac{\phi_{i}^{\theta}}{\phi_{i+1}^{\theta}} \\
-\left(\frac{\phi_{i}}{\phi_{i j}^{*}}\right)^{\sigma-1} \frac{1}{1 / \tilde{\theta}-1}+\left(\frac{\phi_{i}}{\phi_{i j}^{*}}\right)^{(\sigma-1) / \tilde{\beta}} \frac{1}{1 /(\tilde{\theta} \tilde{\beta})-1}
\end{array}\right],
\end{gathered}
$$

where $\phi_{i}, \phi_{i+1}$ is the threshold productivity corresponding to each percentile of firms and this is determined through the expression (30). Similarly, for the period after the liberalization (abusing notation for the rest of this appendix, I denote with a the ex-post variables),

$$
\tilde{L}_{j}^{\alpha}\left(\tilde{y}_{j}\right)^{\gamma}\left(\tilde{y}_{i}\right)^{1-\gamma} \frac{1}{\tilde{\psi}}\left[\begin{array}{c}
\left(\frac{\phi_{i j}^{*}}{\tilde{\phi}_{i j}^{*}} \frac{\phi_{i+1}}{\phi_{i j}^{*}}\right)^{\sigma-1} \frac{1}{1 / \tilde{\theta}-1} \frac{\phi_{i}^{\theta}}{\phi_{i+1}^{\theta}}-\left(\frac{\phi_{i j}^{*}}{\tilde{\phi}_{i j}^{*}} \frac{\phi_{i+1}}{\phi_{i j}^{*}}\right)^{(\sigma-1) / \tilde{\beta}} \frac{1}{1 /(\tilde{\theta} \tilde{\beta})-1} \frac{\phi_{i}^{\theta}}{\phi_{i+1}^{\theta}} \\
-\left(\frac{\phi_{i j}^{*}}{\tilde{\phi}_{i j}^{*}} \frac{\phi_{i}}{\phi_{i j}^{*}}\right)^{\sigma-1} \frac{1}{1 / \tilde{\theta}-1}+\left(\frac{\phi_{i j}^{*}}{\tilde{\phi}_{i j}^{*}} \frac{\phi_{i}}{\phi_{i j}^{*}}\right)^{(\sigma-1) / \tilde{\beta}} \frac{1}{1 /(\tilde{\theta} \tilde{\beta})-1}
\end{array}\right] .
$$

In order to determine the ratio of average sales between the two periods I have to compute the ratios $\frac{\phi_{i j}^{*}}{\tilde{\phi}_{i j}^{*}}, \frac{\tilde{L}_{j}^{\alpha}\left(\tilde{y}_{j}\right)^{\gamma}\left(\tilde{y}_{i}\right)^{1-\gamma}}{L_{j}^{\alpha}\left(y_{j}\right)^{\gamma}\left(y_{i}\right)^{1-\gamma}}$. For the ratio $\frac{\phi_{i j}^{*}}{\tilde{\phi}_{i j}^{*}}$ I use the following expression of $\phi_{i j}^{*}$ in terms of $y_{i}$, 
$y_{j}, L_{j}$,

$$
\left(\phi_{i j}^{*}\right)^{\theta}=\frac{J_{i} b_{i}^{\theta} y_{i}^{1-\gamma}}{\lambda_{i j}} \frac{\left(\frac{1}{1-1 / \tilde{\theta}}-\frac{1}{1-1 /(\tilde{\theta} \tilde{\beta})}\right)}{L_{j}^{1-\alpha} y_{j}^{1-\gamma} \tilde{\psi}} .
$$

Using the assumption that there is no change in $J_{i}, b_{i},{ }^{31}$

$$
\frac{\phi_{i j}^{*}}{\tilde{\phi}_{i j}^{*}}=\left(\frac{\tilde{\lambda}_{i j}}{\lambda_{i j}} \frac{\left(y_{i}\right)^{1-\gamma}}{\left(\tilde{y}_{i}\right)^{1-\gamma}} \frac{\tilde{L}_{j}^{1-\alpha}\left(\tilde{y}_{j}\right)^{1-\gamma}}{L_{j}^{1-\alpha}\left(y_{j}\right)^{1-\gamma}}\right)^{1 / \theta}
$$

Therefore, the only required information to determine the yet undetermined ratios $\frac{\phi_{i j}^{*}}{\tilde{\phi}_{i j}^{*}}, \frac{\tilde{L}_{j}^{\alpha}\left(\tilde{y}_{j}\right)^{\gamma}\left(\tilde{y}_{i}\right)^{1-\gamma}}{L_{j}^{\alpha}\left(y_{j}\right)^{\gamma}\left(y_{i}\right)^{1-\gamma}}$ is $\lambda_{i j}, L_{j}, y_{j}$. I describe how I construct these ratios in the next paragraph.

For the particular calibration exercise that I perform, $i$ corresponds to Mexico $(M)$ and $j$ to the US $(U)$. Data on $L_{M}, L_{U}$ are from World Development Indicators. To obtain $y_{M}, W_{U}, \mathrm{I}$ use data on manufacturing absorption obtained from the OECD STAN database for the years 1990-92 and 1997-99 and divide these data by the population of each country. Manufacturing absorption is calculated as gross output minus exports plus imports. I use data for the sectors that appear in the OECD trade by commodity data, namely i) agriculture, hunting, forestry and fishing ii) mining and quarrying iii) total manufacturing and iv) electricity, gas and water supply. Notice that for 1990 the database does not provide data on exports and imports for US for sectors i),ii) and iv). I choose to consider averages over 1991-92 and 1998-99 for the manufacturing absorption of US instead of using exports and imports from another source. In fact the trade sectors i),ii) and iv) is less than 1/10 of the one of sector iii) and influences the result to a minimal degree. I finally pick the ratio $\tilde{\lambda}_{M U} / \lambda_{M U}$ so that I generate the overall increase in trade among goods traded during 1990-92. This corresponds (all else equal) in a change of the variable trade cost by around $9.5 \%$ for the model with $\beta=1$ and around 12.5 to the model with $\beta=0$ (see equation 20 ).

\footnotetext{
${ }^{31}$ Extending to the case where $J_{i}, b_{i}$ change would deliver the same results (but complicate notation).
} 


\begin{tabular}{|l|r|c|c|c|c|c|c|c|c|c|c|c|c|}
\hline & $\begin{array}{c}\text { "Newly } \\
\text { non- }\end{array}$ & \multicolumn{1}{|c|}{$\begin{array}{c}\text { "Newly } \\
\text { traded" }\end{array}$} & \multicolumn{10}{|c|}{ "Previously Traded" } \\
& by category \\
\hline & traded" & 1 & 2 & 1 & 2 & 3 & 4 & 5 & 6 & 7 & \multicolumn{1}{|c|}{8} & 9 & 10 \\
\hline Share of '90-'92 trade & .13 & .85 & .12 & .01 & .05 & .11 & .23 & .45 & .86 & 1.78 & 3.52 & 7.64 & 84.28 \\
\hline Share of '97-'99 trade & .00 & 3.46 & .30 & .17 & .28 & .86 & .64 & 1.68 & 1.67 & 2.31 & 7.23 & 9.26 & 72.13 \\
\hline Share of new trade & - & 4.84 & .38 & .26 & .40 & 1.25 & .86 & 2.33 & 2.10 & 2.58 & 9.17 & 10.11 & 65.71 \\
\hline
\end{tabular}

Table 1: Percentage trade shares of "newly nontraded," "newly traded," and "previously traded" goods

\begin{tabular}{|l|c|c|}
\hline & $\begin{array}{c}\text { Share of '90-'92 "previously } \\
\text { traded" goods trade }\end{array}$ & $\begin{array}{c}\text { Share of '97-'99 "previously } \\
\text { traded" goods trade }\end{array}$ \\
\hline US imports from Mex $(6$ digit HS) $(\%)$ & 15.0 & 25.1 \\
\hline Endogenous cost model $(\beta=1)$ & 15.0 & 24.9 \\
\hline Fixed cost model $(\beta=0)$ & 15.0 & 15.0 \\
\hline
\end{tabular}

Table 2: Percentage trade share of the goods that constitute the $15 \%$ Least Traded "Previously Traded" goods in 1990-92

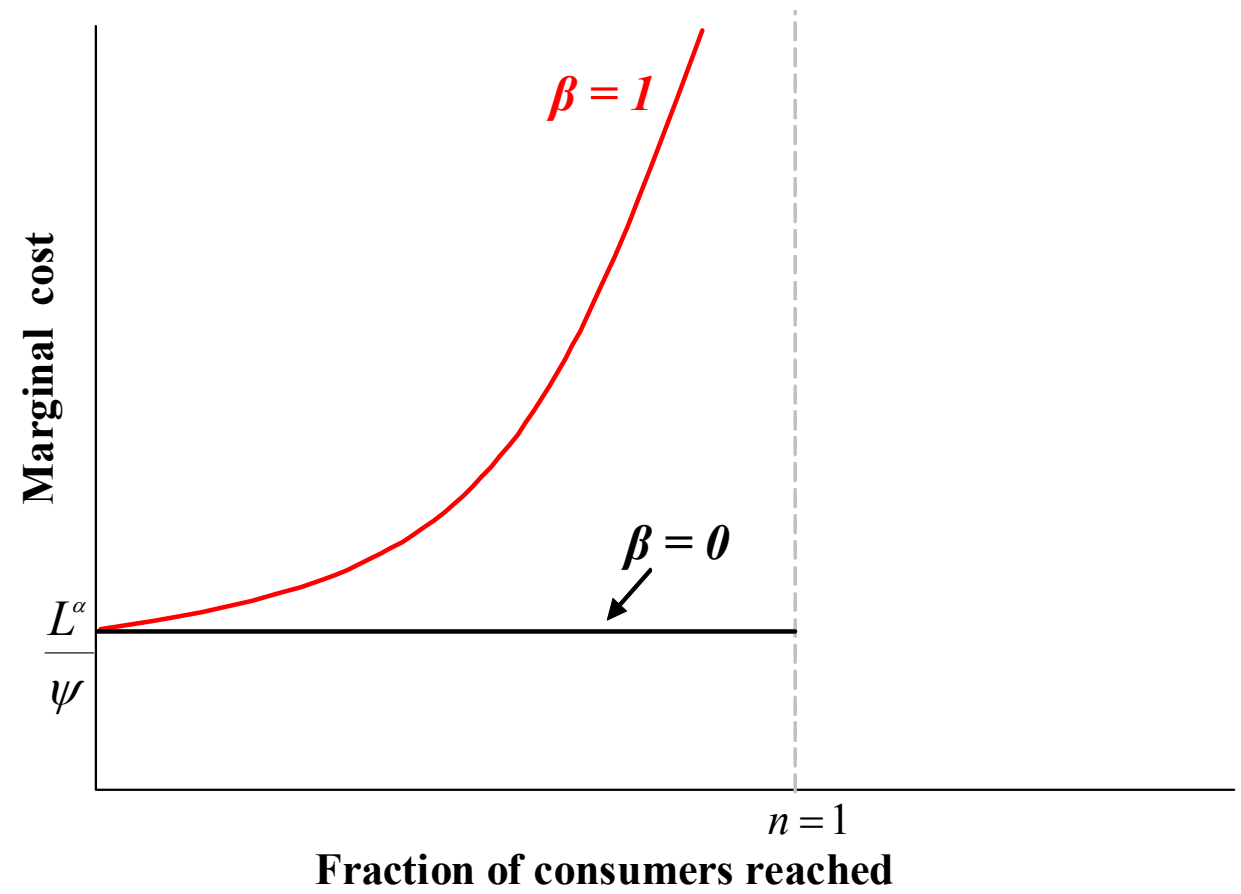

Figure 1: Marginal cost to reach additional consumers under different $\beta$ 's 


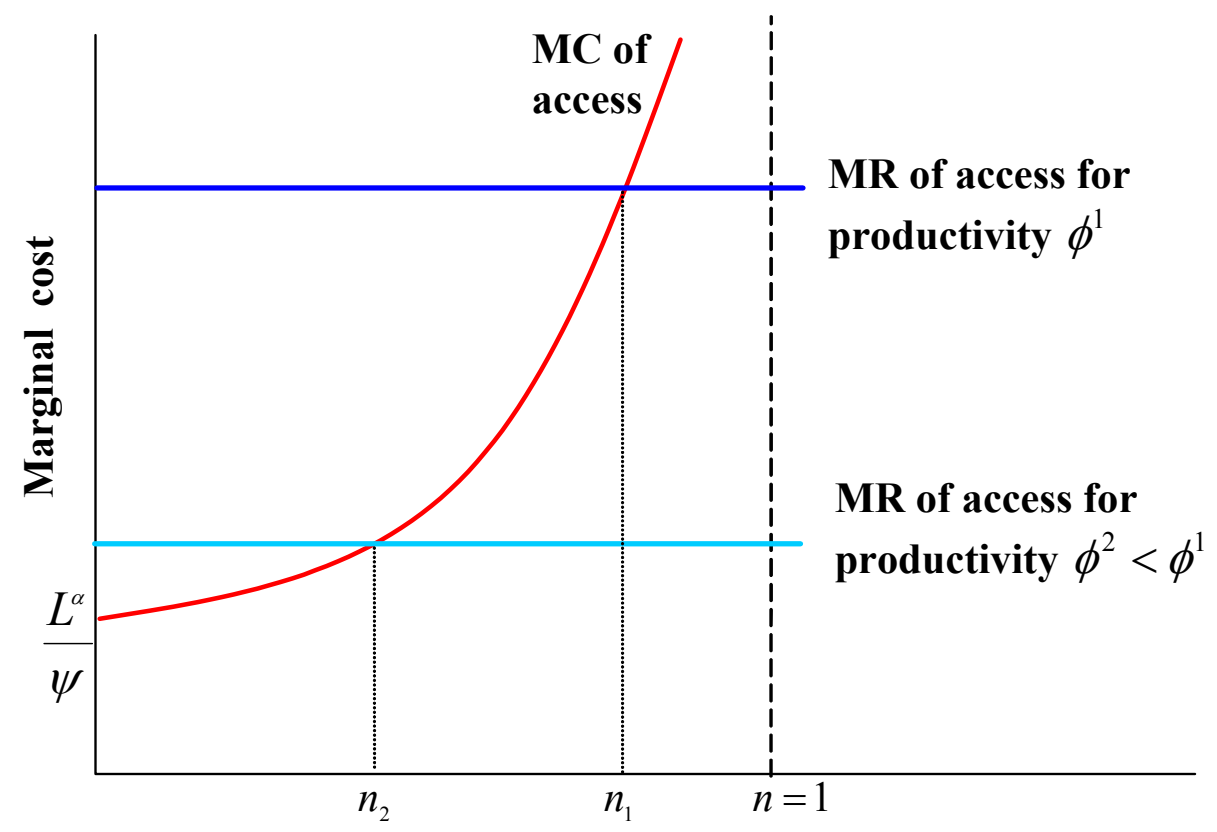

Fraction of consumers reached

Figure 2: Productivity and market access

\section{Fraction of consumers}

reached $(n)$

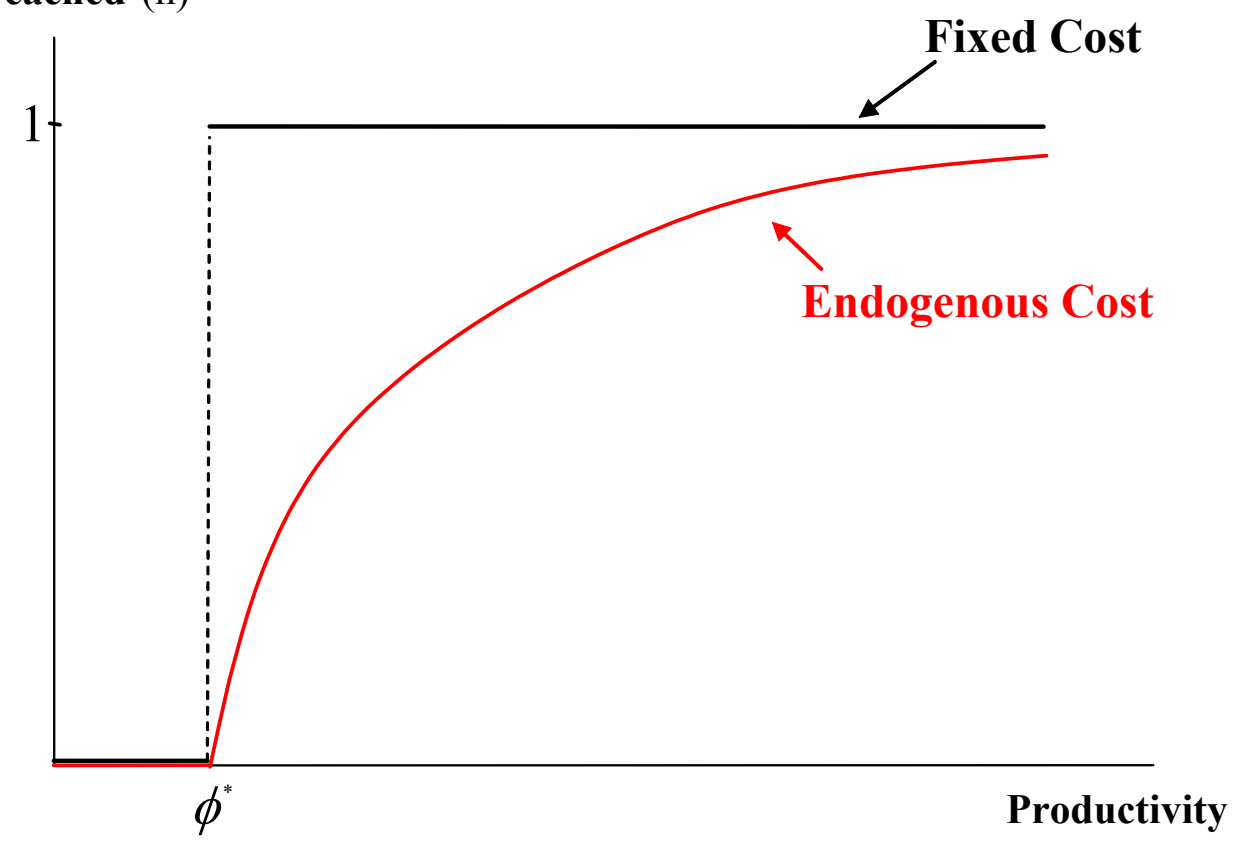

Figure 3: Fraction of consumers reached and productivity 


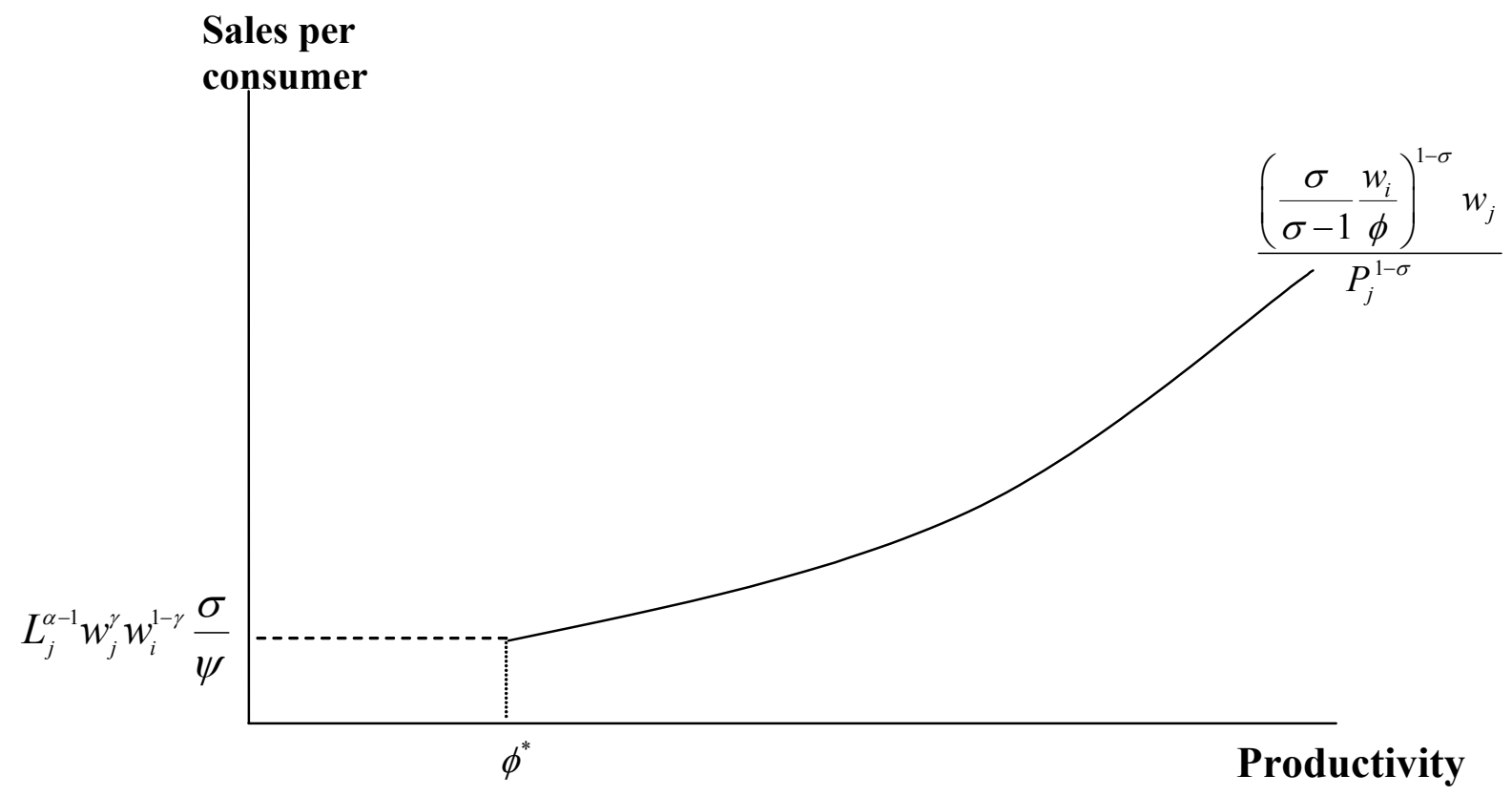

Figure 4: Intensive margin of sales and productivity

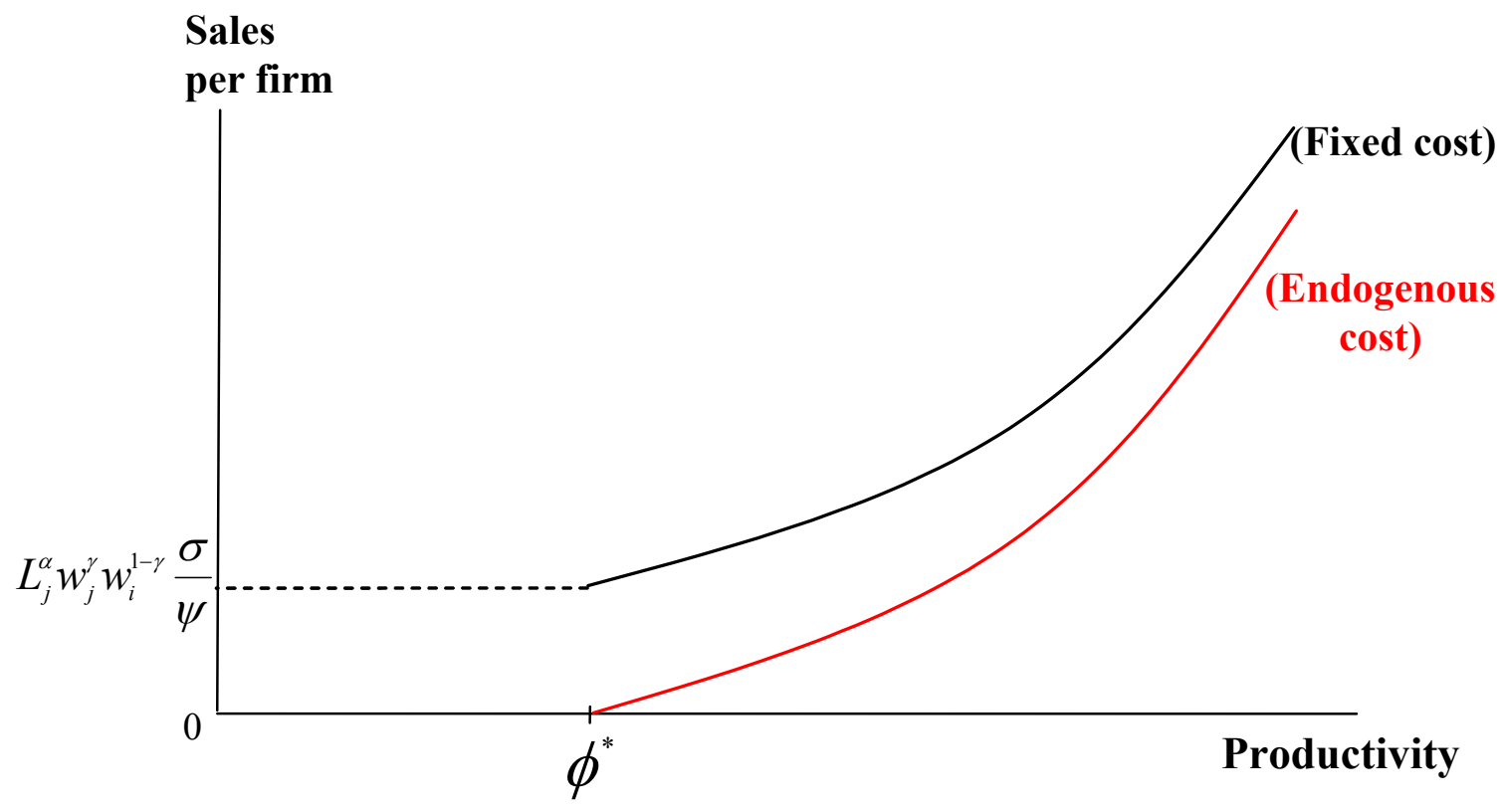

Figure 5: Sales per firm as a function of productivity in the two models 


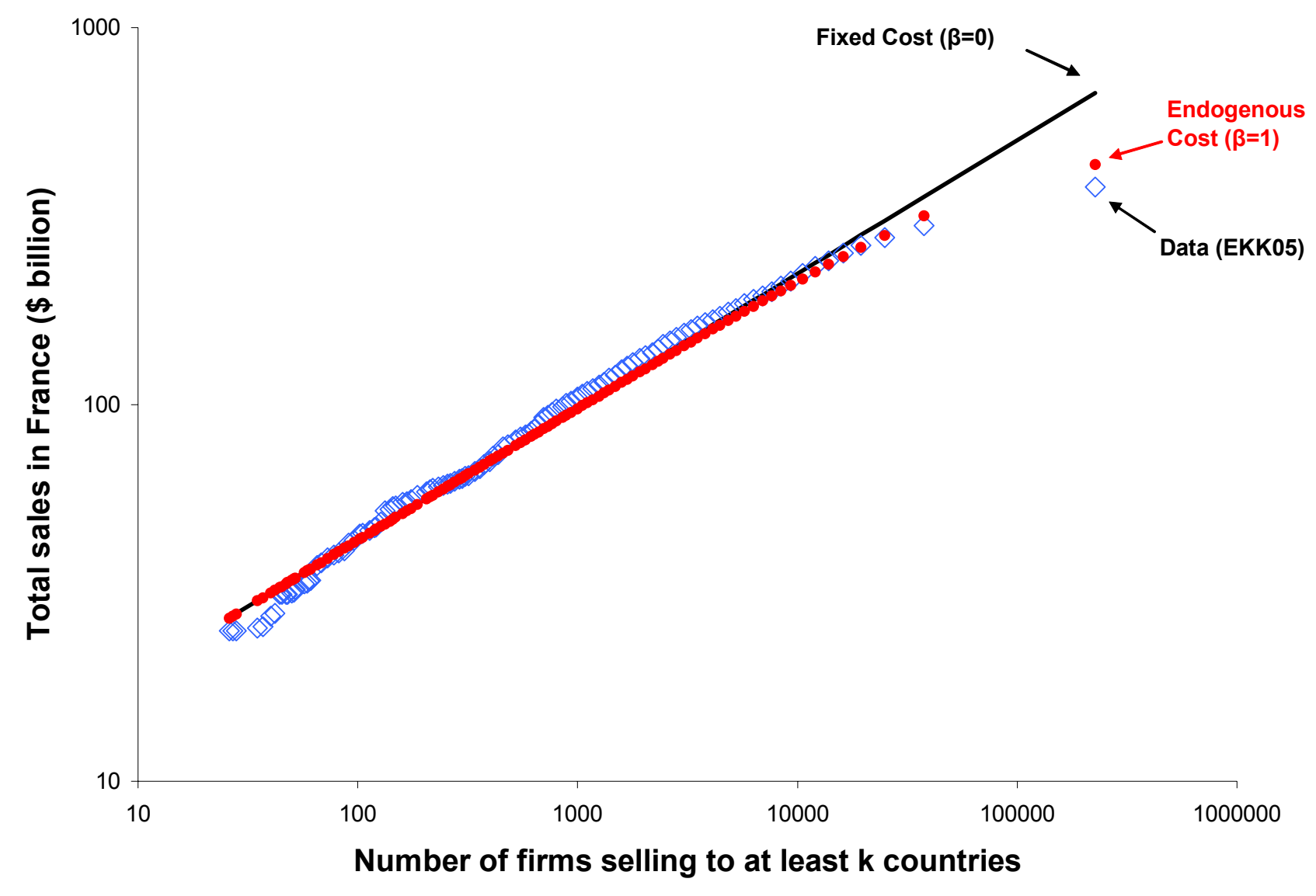

Figure 6: Total sales in France and number of firms selling to at least $k$ countries 


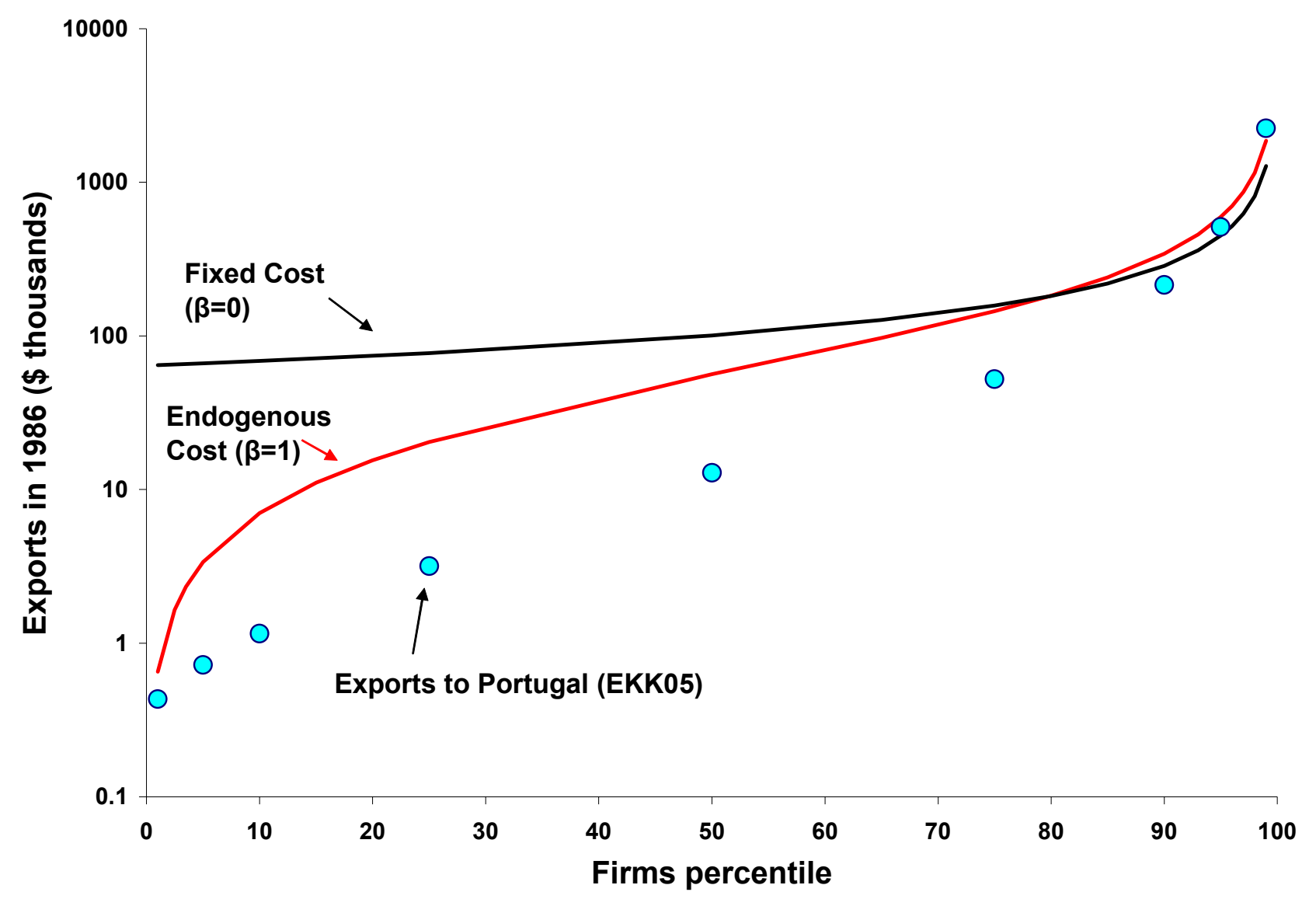

Figure 7: Predicted and actual distribution of export sales of French firms to Portugal 


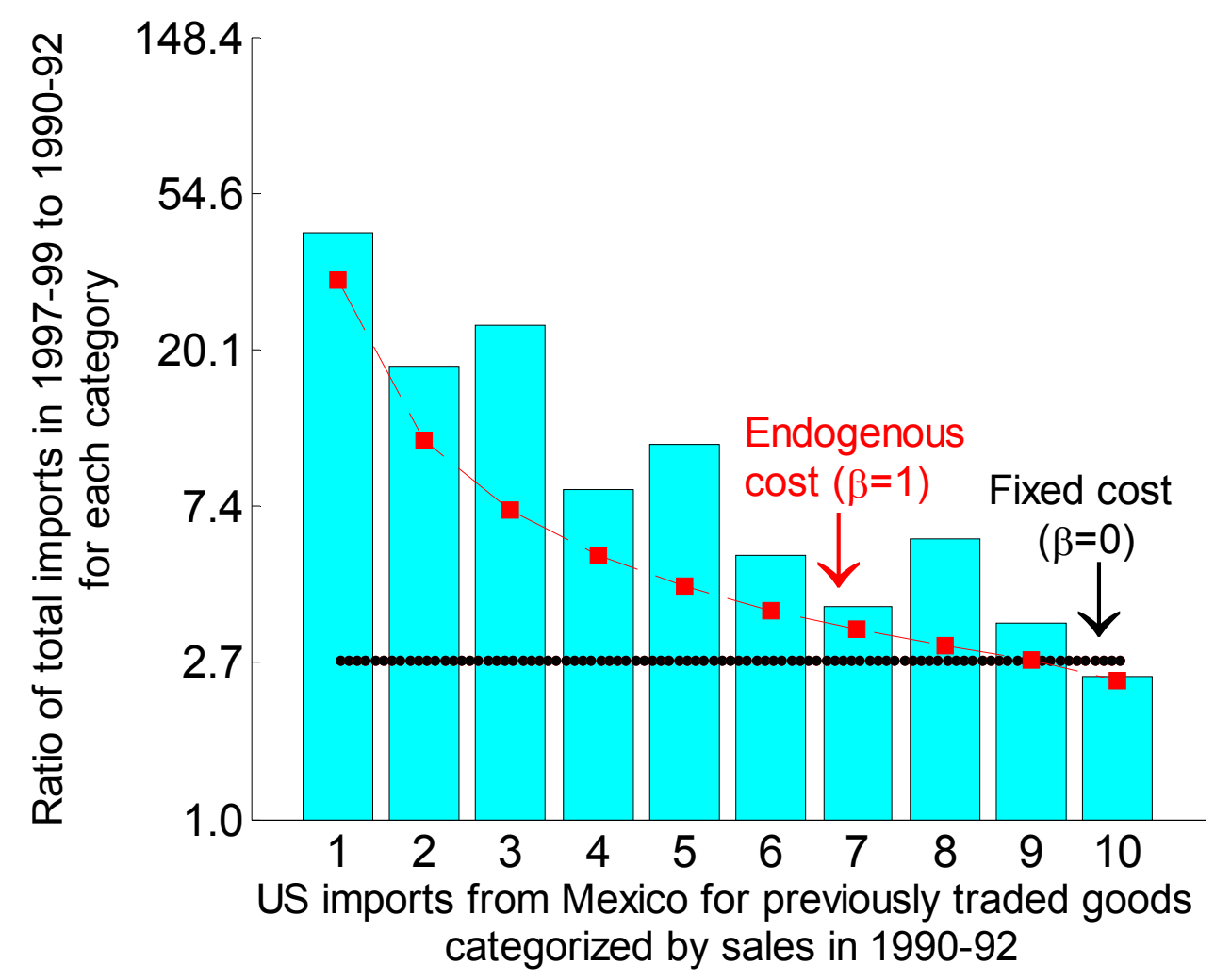

Figure 8: Predicted and actual ratio of US imports from Mexico in '97-99 to '90-92 for each category of goods. 

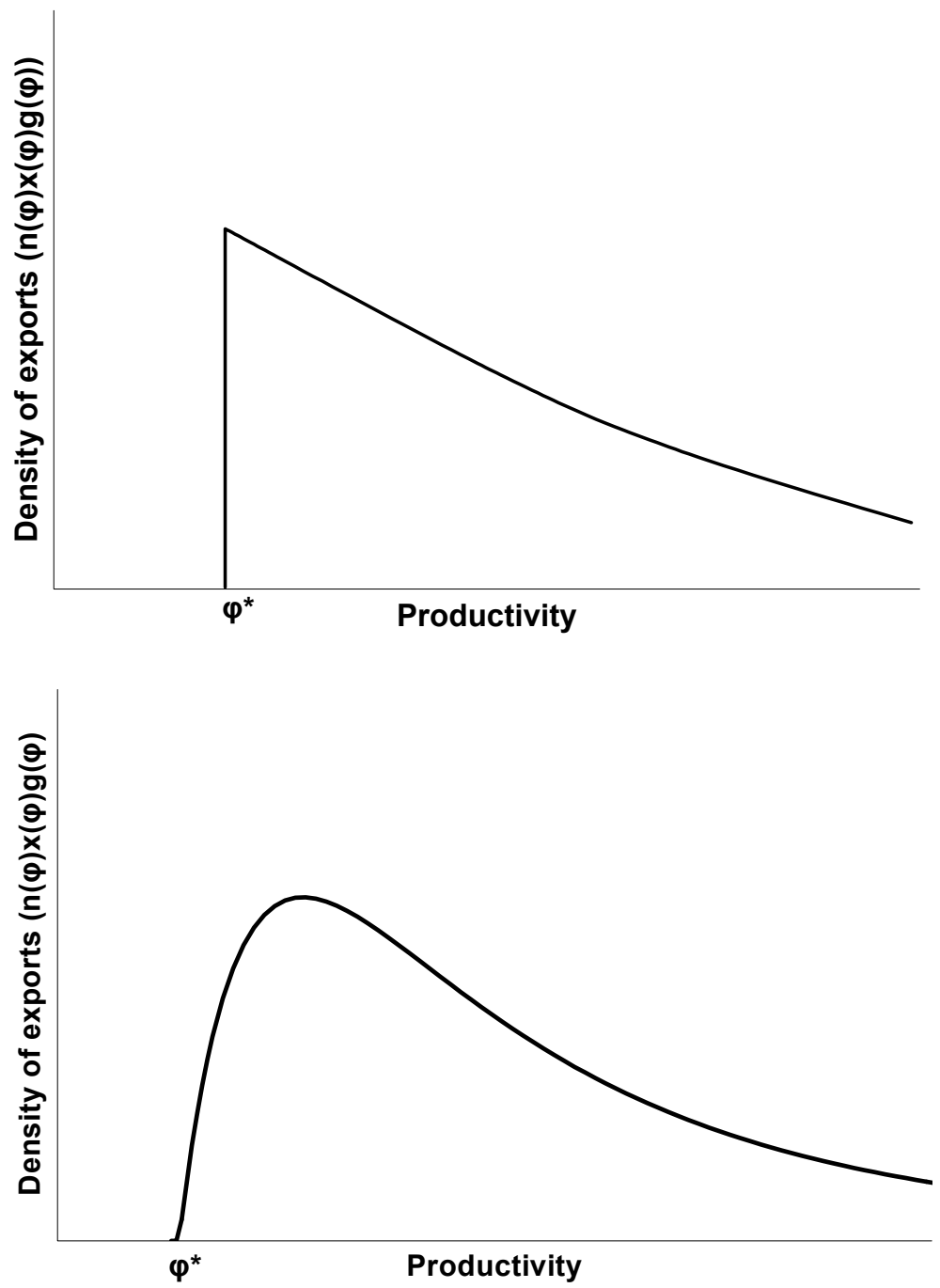

Figure 9: Density of exports in the fixed cost and the endogenous cost models 


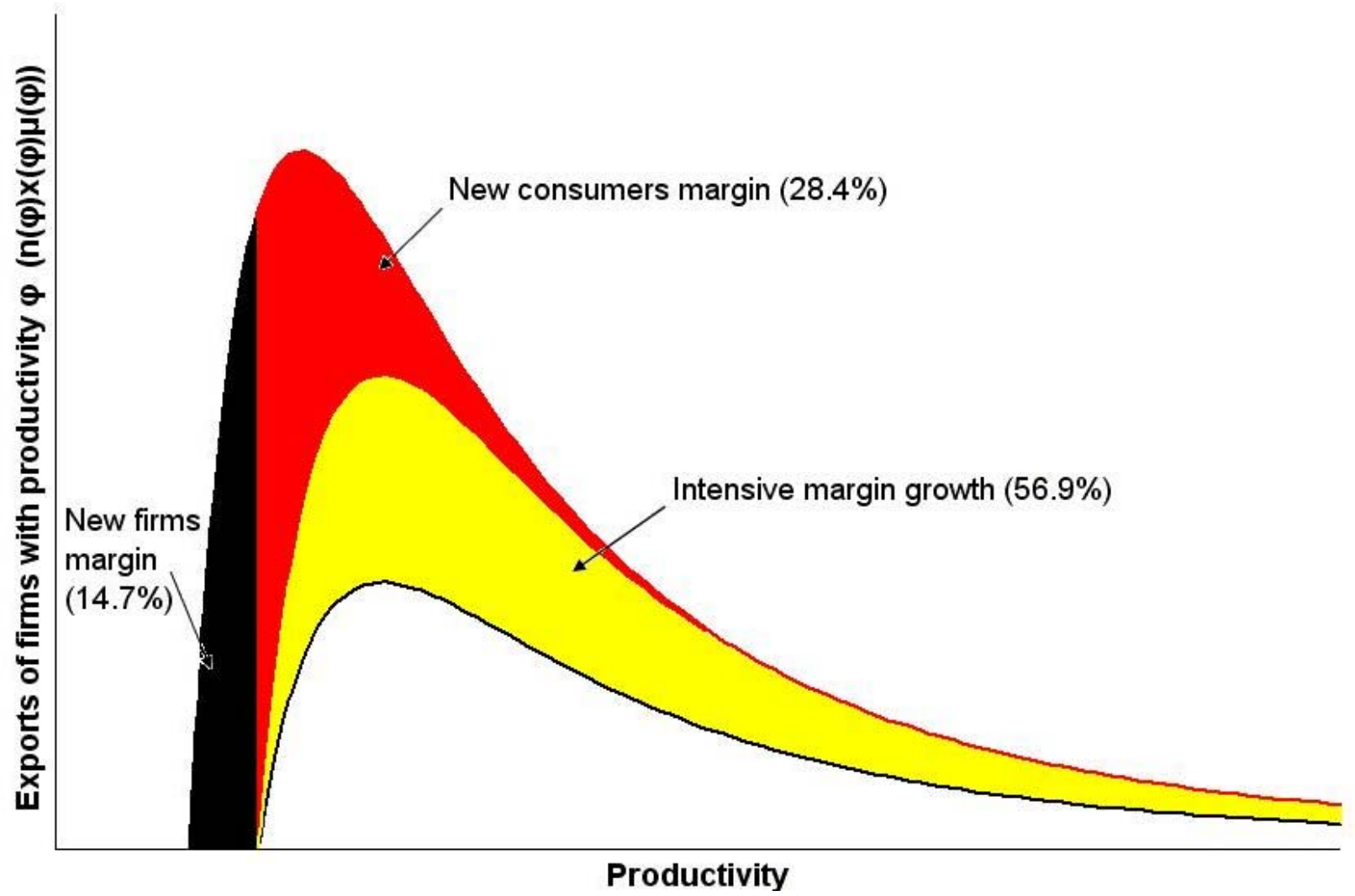

Figure 10: Trade liberalization and the margins of trade 